\title{
Triosephosphate Isomerase from Mycobacterium tuberculosis as Potential Target to Develop a New Anti-TB Drug
}

\author{
David Hernández-Viveros ${ }^{1}$, Donato A. Rechy-Iruretagoyena ${ }^{1}$, Raúl Díaz-Molina ${ }^{1}$, José Luis Vique- \\ Sánchez ${ }^{1, * \text { (D) }}$
}

1 Medical School, Campus Mexicali, Autonomous University of Baja California, BC, México

* Correspondence: jvique@uabc.edu.mx (J.L.V.-S.);

Scopus Author ID 57195635710

Received: 1.09.2021; Revised: 15.10.2021; Accepted: 18.10.2021; Published: 21.10.2021

\begin{abstract}
Tuberculosis (TB) is possibly the most prevalent infectious disease in the world, reports from the World Health Organization (WHO) indicate that TB is one of the top 10 causes of death and an estimated 10 million people worldwide, in addition, there are increasing the TB resistant to conventional antibiotics, multidrug-resistant tuberculosis (MDR-TB) and extensively drug-resistant tuberculosis (XDR-TB). Lastly, TB has become more important and requires more attention since it has been proposed as a risk factor for the severity of COVID-19. Therefore, the need to develop new anti-TB drugs. In this study, we propose to use the glycolytic enzyme triosephosphate isomerase from Mycobacterium tuberculosis (MtTIM) as a therapeutic target against TB. The triosephosphate isomerase (TIM) is a target used in different proposals to develop new drugs against different organisms. The MtTIM is an extremely attractive drug target due to the characteristics of its amino acids sequence. In addition, it has been determined that this enzyme (MtTIM) is necessary for the viability of in vitro and in vivo cultures of Mycobacterium tuberculosis. In this way, using the MtTIM as a therapeutic target, we propose potential compounds against MtTIM by molecular docking.
\end{abstract}

Keywords: MtTIM inhibitors; triosephosphate isomerase; docking; Mycobacterium tuberculosis.

(C) 2021 by the authors. This article is an open-access article distributed under the terms and conditions of the Creative Commons Attribution (CC BY) license (https://creativecommons.org/licenses/by/4.0/).

\section{Introduction}

Tuberculosis (TB), caused by the bacillus Mycobacterium tuberculosis, is possibly the most prevalent infectious disease globally. The World Health Organization (WHO) indicates that TB is in the top ten causes of death and an estimated ten million cases worldwide per year, which shows a challenge for public health services. In addition, other increasing factors that favor TB, such as the development of $M$. tuberculosis resistant to conventional antibiotics, multidrug-resistant tuberculosis (MDR-TB) and extensively drug-resistant tuberculosis (XDRTB) [1-4], for which there are several anti-tuberculosis drugs [5, 6].

Lately, TB has become more important since pulmonary TB as a risk factor for the severity of COVID-19 has been identified, in addition to the fact that additivity or synergy can occur between the two diseases in their pathological processes [7-13].

Therefore, it demonstrates the need to improve the therapeutic options and develop more efficient drugs against $M$. tuberculosis. Currently, there are different proposals for the development of drugs using new therapeutic targets against this disease [6, 14, 15]. An example is the development of enzyme inhibitors; against cytochrome bd oxidase [16], probable cation- 
transporting ATPase F (CtpF) [17], zinc metalloprotease 1 (Zmp1) [18], $\alpha$-subunit of tryptophan synthase ( $\alpha$-TRPS) [19], decaprenylphosphoryl-beta-D-ribose oxidase (DprE1) [20], cytochrome bc1 complex cytochrome b subunit (QcrB) [21], and in this study is proposed the glycolytic enzyme, triosephosphate isomerase (TIM).

TIM is an enzyme that participates in glycolysis and gluconeogenesis, carrying out the interconversion between glyceraldehyde-3-phosphate and dihydroxyacetone phosphate [22], different proposals focus on TIM from different organisms to develop new drugs [23-29]. Hence, TIM from Mycobacterium tuberculosis (MtTIM), is one of the key enzymes of the glycolytic pathway, making it an attractive drug target [30, 31]. It has been shown that the functions of this enzyme influence the process of glycolysis and gluconeogenesis and that this enzyme (MtTIM) is necessary for the viability of in vitro and in vivo cultures [32].

In this study, MtTIM is proposed as a therapeutic target to develop anti-TB drugs, in which molecular docking is carried out using a library of 1772 bioactive agents that contain compounds with interaction in different proteins. In addition, is evaluated the interaction with a compound reported with inhibitory effect on TIM from Entamoeba histolytica (EhTIM) [29]; in this way, the MtTIM is evaluated for that it can be a new therapeutic target, as well as compounds with inhibitory potential are proposed.

\section{Materials and Methods}

\subsection{Preparation of receptor protein and selection of binding sites.}

Atomic coordinates were obtained from the Protein Data Bank [33], triosephosphate isomerase of Mycobacterium tuberculosis (MtTIM) and Homo sapiens (HsTIM) structures (PDB codes 3TA6 and 4POC, respectively), were used for molecular docking using Molecular Operating Environment (MOE) following procedures previously reported [34-36]. The potential binding sites were determined using a "site finder" in MOE, which identifies regions of high probability to interact and selects preferentially hydrophobic sites [37-39].

\subsection{Compound library used for molecular docking.}

The Bioactives Collection Stock screening library (Chembridge Corp.- Hit2Lead.com $[40,41])$ was used for molecular docking. This collection of bioactive molecules contains 1772 compounds to evaluate the interaction with MtTIM, and we used the D4 compound with effect on triosephosphate isomerase of Entamoeba histolytica [29].

\subsection{Molecular docking.}

For molecular docking, 18 potential binding sites were used for MtTIM and were generated up to 100 conformers from each compound to interact (compound library against MtTIM), following procedures previously reported [34, 36]. The high-throughput molecular docking was carried out by the software MOE, and the analysis of ligand interaction per amino acid at MOE and Protein-Ligand Interaction Profiler [39, 41-43].

\subsection{Selection of the best five compounds.}

To select the best five compounds, the results of up to 30 conformers from each compound were used to select them. It was determining the binding free energy ( $\Delta$ Gbinding) of each complex (Ligand-Protein), as previously reported [34, 36] using MOE [44, 45]. With 
these results, the best averages of $\Delta \mathrm{G}$ binding were determined between MtTIM and each compound and the standard deviation for each one using the Excel software (Microsoft-365). The better compounds selected were evaluated in HsTIM to discuss the selectivity only for MtTIM. In addition, it shows the description of chemical properties by PhysChem - ACD/Labs [46] and the theoretical toxicity (carcinogenicity and mutagenicity) [47-49].

\section{Results and Discussion}

\subsection{Selection of compounds by Molecular Docking.}

In this study were determined the potential interaction of the Bioactives Collection Stock screening library from Chembridge Corp. (1772 compounds) [40, 41] and D4 compound in MtTIM for this were generated up to 100 conformers of each compound to interact in the 18 potential binding sites (Figure 1) by molecular docking [34, 36]. The selection criteria for the best five compounds was based on the calculation of the average of $\Delta$ Gbinding of each compound (Table 1). Using the best five values of their conformers of each compound, were determined the average of $\Delta$ Gbinding between -9.83 to $-18.70 \mathrm{kcal} \mathrm{mol}^{-1}$ for MtTIM and -6.31 to $-7.90 \mathrm{kcal} \mathrm{mol}^{-1}$ for HsTIM (Table 2, and details on the supplementary material Table S1 and S2). The analysis of the interaction of the best five conformers from the five compounds selected (depicted here as T1 - T5) and D4 compound with MtTIM and HsTIM were carried out with the interaction report (Table 3 and details in Table S3 - S14). All averages of $\Delta$ Gbinding calculated are related to the number of interactions generated by the conformers analyzed from the molecular docking results (mainly hydrogen bonding, Table S3 - S14).

In addition, the tables of the description of the theoretical toxicity (Table S15), ADME characteristics (Table S16), and chemical properties of each compound (T1 - T5 and D4, Table S17), are in the supplemental material.

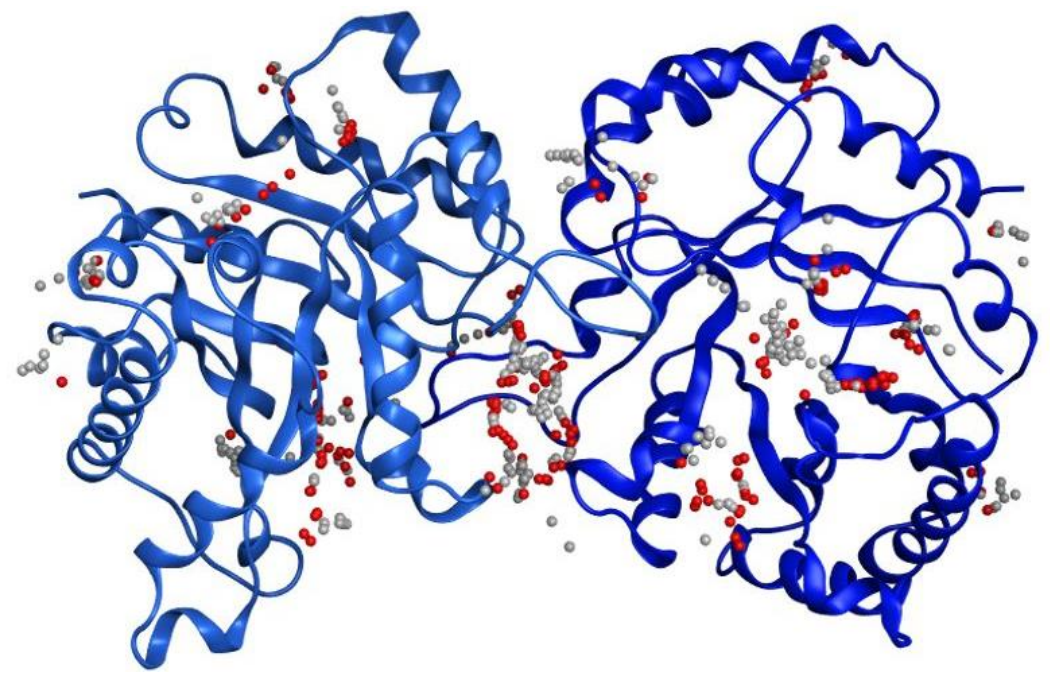

Figure 1. MtTIM (Blue) shows the 18 potential binding sites in balls red and white, determined by "site finder" in MOE for molecular docking.

Table 1. PubChem CID and Structure of the best compounds, T1 - T5 and D4 compounds.

T1.- 1769482<smiles>COC(=O)c1ccccc1C(=O)c1ccc(C(C)C(=O)Cc2ccc(OC)cc2)cc1</smiles>

T2.- 1334501

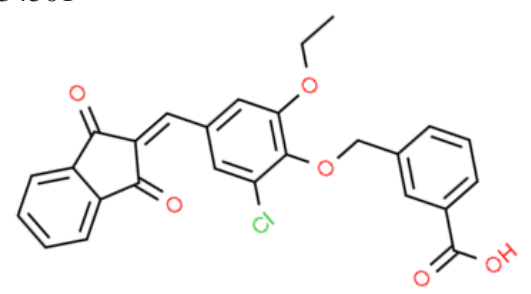




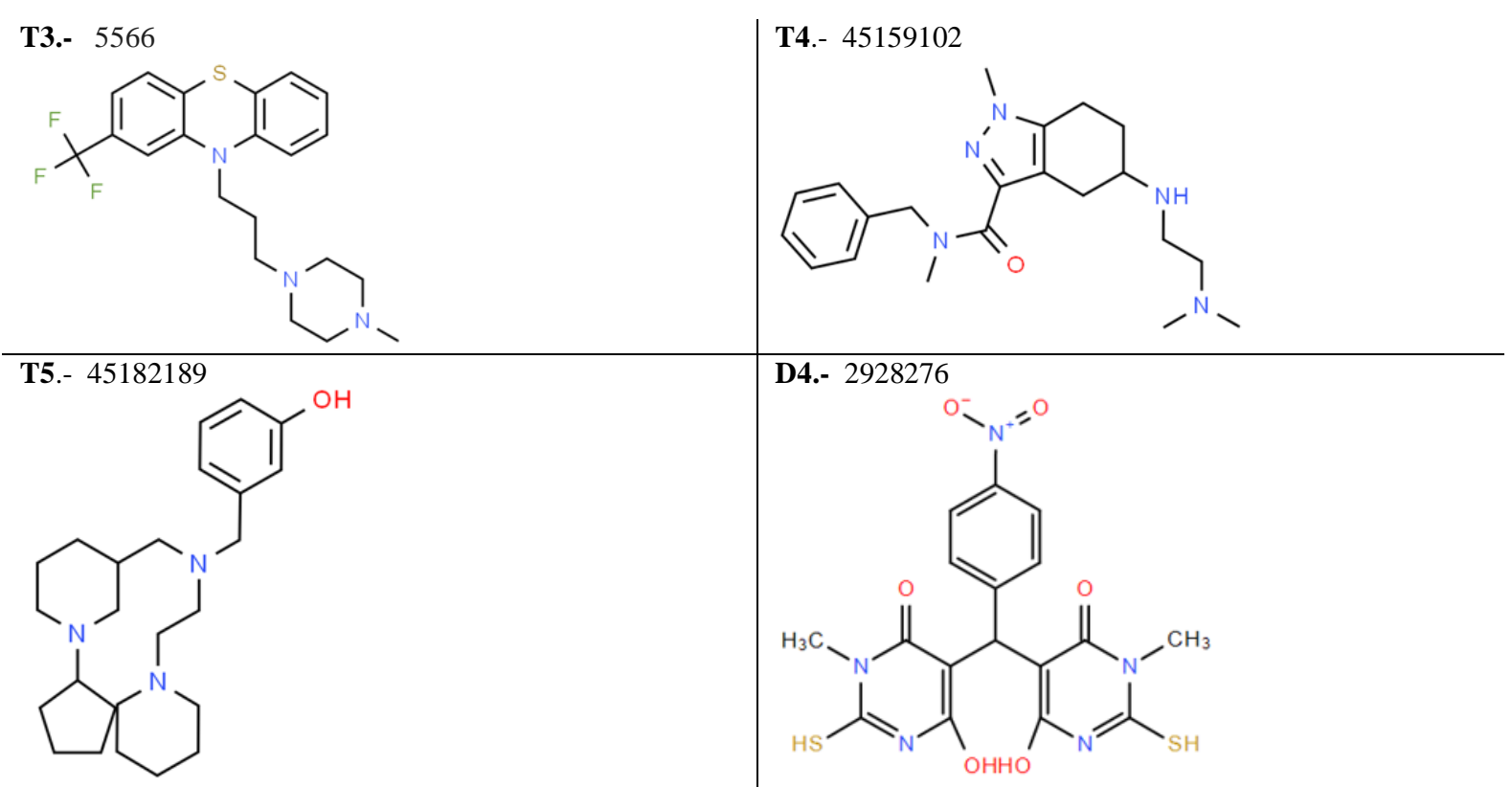

Table 2. Average of $\Delta \mathrm{G}_{\mathrm{binding}}\left(\mathrm{kcal} \mathrm{mol}^{-1}\right)$ and $\mathrm{SD}$ of $\mathrm{T} 1$ - T5 and D4 compounds in MtTIM and HsTIM.

\begin{tabular}{c|l|c} 
Compound & \multicolumn{1}{|c|}{ MtTIM } & HsTIM \\
\hline T1 & $-12.02 \pm 4.17$ & $-7.30 \pm 0.21$ \\
\hline T2 & $-12.21 \pm 2.34$ & $-7.69 \pm 0.20$ \\
\hline T3 & $-9.83 \pm 3.93$ & $-6.31 \pm 0.16$ \\
\hline T4 & $-18.70 \pm 5.03$ & $-7.90 \pm 0.34$ \\
\hline T5 & $-11.84 \pm 5.14$ & $-6.71 \pm 0.15$ \\
\hline D4 & $-11.64 \pm 1.20$ & $-6.83 \pm 0.71$
\end{tabular}

Table 3. PubChem CID, Canonical SMILES, Interaction with amino acids in MtTIM and HsTIM, Ames test and strain used (positive or negative) and $\mathrm{LD}_{50}[47,49]$.

\begin{tabular}{|c|c|c|c|c|}
\hline PubChem CID & Canonical SMILES & $\begin{array}{l}\text { Interaction with } \\
\text { amino acids in AXL } \\
\text { (Table } S 2-S 11 \text { ), in } \\
\text { bold are greater } \\
\text { interaction. }\end{array}$ & $\begin{array}{l}\text { Interaction with } \\
\text { amino acids in AXL } \\
\text { (Table } S 2-S 11 \text { ), in } \\
\text { bold are greater } \\
\text { interaction. }\end{array}$ & $\begin{array}{l}\text { PreADMET } \\
\text { Ames test and LD } \\
\\
\text {-TA100_10RL } \\
\text {-TA100_NA } \\
\text {-TA1535_10R } \\
\text {-TA1535_NA } \\
\text { Predicted LD } 5 \text { mo/kg }\end{array}$ \\
\hline T1.- 1769482 & $\begin{array}{l}\mathrm{COC} 1=\mathrm{CC}=\mathrm{C}(\mathrm{C}=\mathrm{C} 1) \mathrm{CC}(=\mathrm{O}) \mathrm{NC} 2= \\
\mathrm{CC}=\mathrm{C}(\mathrm{C}=\mathrm{C} 2) \mathrm{C}(=\mathrm{O}) \mathrm{NC} 3=\mathrm{CC}=\mathrm{CC}= \\
\mathrm{C} 3 \mathrm{C}(=\mathrm{O})[\mathrm{O}-]\end{array}$ & $\begin{array}{l}\text { His74, Asp82, Arg103, } \\
\text { Thr105, Lys117, } \\
\text { Leu136, His147, Ile177, } \\
\text { Gly178 }\end{array}$ & $\begin{array}{l}\text { Lys5, Lys58, Trp90, } \\
\text { Arg98, Arg99, } \\
\text { Asp106, Ser158 }\end{array}$ & $\begin{array}{l}\text { Mutagen } \\
\text {-Negative } \\
\text {-Negative } \\
\text {-Negative } \\
\text {-Positive } \\
5000 \mathrm{mg} / \mathrm{kg} \\
\end{array}$ \\
\hline T2.- 1334501 & $\begin{array}{l}\mathrm{CCOC} 1=\mathrm{C}(\mathrm{C}(=\mathrm{CC}(=\mathrm{C} 1) \mathrm{C}=\mathrm{C} 2 \mathrm{C}(= \\
\mathrm{O}) \mathrm{C} 3=\mathrm{CC}=\mathrm{CC}=\mathrm{C} 3 \mathrm{C} 2=\mathrm{O}) \mathrm{Cl}) \mathrm{OCC} 4 \\
=\mathrm{CC}(=\mathrm{CC}=\mathrm{C} 4) \mathrm{C}(=\mathrm{O}) \mathrm{O}\end{array}$ & $\begin{array}{l}\text { Lys12, Thr105, Leu136, } \\
\text { Trp175, Ile177, Gly180 }\end{array}$ & $\begin{array}{l}\text { Asn65, Tyr67, Glu77, } \\
\text { Arg98 }\end{array}$ & $\begin{array}{l}\text { Mutagen } \\
\text {-Negative } \\
\text {-Negative } \\
\text {-Negative } \\
\text {-Negative } \\
1600 \mathrm{mg} / \mathrm{kg} \\
\end{array}$ \\
\hline T3.- 5566 & $\begin{array}{l}\mathrm{CN} 1 \mathrm{CCN}(\mathrm{CC} 1) \mathrm{CCCN} 2 \mathrm{C} 3=\mathrm{CC}=\mathrm{C} \\
\mathrm{C}=\mathrm{C} 3 \mathrm{SC} 4=\mathrm{C} 2 \mathrm{C}=\mathrm{C}(\mathrm{C}=\mathrm{C} 4) \mathrm{C}(\mathrm{F})(\mathrm{F}) \mathrm{F}\end{array}$ & $\begin{array}{l}\text { Asp33, Tyr106, His 107, } \\
\text { Asp231 }\end{array}$ & $\begin{array}{l}\text { Asp36, Glu107, } \\
\text { Val142, Glu145, } \\
\text { Glu186, Lys193, } \\
\text { Gln223, Asp225 }\end{array}$ & $\begin{array}{l}\text { Mutagen } \\
\text {-Negative } \\
\text {-Negative } \\
\text {-Negative } \\
\text {-Negative } \\
424 \mathrm{mg} / \mathrm{kg} \\
\end{array}$ \\
\hline T4.- 45159102 & $\begin{array}{l}\mathrm{CN} 1 \mathrm{C} 2=\mathrm{C}(\mathrm{CC}(\mathrm{CC} 2) \mathrm{NCCN}(\mathrm{C}) \mathrm{C}) \mathrm{C} \\
(=\mathrm{N} 1) \mathrm{C}(=\mathrm{O}) \mathrm{N}(\mathrm{C}) \mathrm{CC} 3=\mathrm{CC}=\mathrm{CC}=\mathrm{C} 3\end{array}$ & Asp33, Arg63 & $\begin{array}{l}\text { Arg98, Val101, } \\
\text { Phe102, Gly103 }\end{array}$ & $\begin{array}{l}\text { Mutagen } \\
\text {-Negative } \\
\text {-Negative } \\
\text {-Negative }\end{array}$ \\
\hline
\end{tabular}




\begin{tabular}{|c|c|c|c|c|}
\hline PubChem CID & Canonical SMILES & $\begin{array}{l}\text { Interaction with } \\
\text { amino acids in } A X L \\
\text { (Table } S 2-S 11 \text { ), in } \\
\text { bold are greater } \\
\text { interaction. }\end{array}$ & $\begin{array}{l}\text { Interaction with } \\
\text { amino acids in } A X L \\
\text { (Table } S 2-S 11 \text { ), in } \\
\text { bold are greater } \\
\text { interaction. }\end{array}$ & $\begin{array}{l}\text { PreADMET } \\
\text { Ames test and LD } \\
\\
\text {-TA100_10RL } \\
\text {-TA100_NA } \\
\text {-TA1535_10R } \\
\text {-TA1535_NA } \\
\text { Predicted LD } 50 \text { mg/kg }\end{array}$ \\
\hline & & & & $\begin{array}{l}\text {-Negative } \\
300 \mathrm{mg} / \mathrm{kg}\end{array}$ \\
\hline T5.- 45182189 & $\begin{array}{l}\mathrm{C} 1 \mathrm{CCN}(\mathrm{CC} 1) \mathrm{CCN}(\mathrm{CC} 2 \mathrm{CCCN}(\mathrm{C} 2) \\
\mathrm{C} 3 \mathrm{CCCC} 3) \mathrm{CC} 4=\mathrm{CC}(=\mathrm{CC}=\mathrm{C} 4) \mathrm{O}\end{array}$ & $\begin{array}{l}\text { Asp33, Arg104, } \\
\text { Glu109, Asp110, } \\
\text { Asp209 }\end{array}$ & $\begin{array}{l}\text { Glu104, Asp106, } \\
\text { Glu133, Glu145 }\end{array}$ & $\begin{array}{l}\text { Mutagen } \\
\text {-Negative } \\
\text {-Negative } \\
\text {-Positive } \\
\text {-Negative } \\
410 \mathrm{mg} / \mathrm{kg}\end{array}$ \\
\hline D4.- 2928276 & $\begin{array}{l}\mathrm{CN} 1 \mathrm{C}(=\mathrm{C}(\mathrm{C}(=\mathrm{O}) \mathrm{NC} 1=\mathrm{S}) \mathrm{C}(\mathrm{C} 2=\mathrm{CC} \\
=\mathrm{C}(\mathrm{C}=\mathrm{C} 2)[\mathrm{N}+](=\mathrm{O})[\mathrm{O}- \\
]) \mathrm{C} 3=\mathrm{C}(\mathrm{N}(\mathrm{C}(=\mathrm{S}) \mathrm{NC} 3=\mathrm{O}) \mathrm{C}) \mathrm{O}) \mathrm{O}\end{array}$ & $\begin{array}{l}\text { Lys12, Asn14, Glu102, } \\
\text { Glu172, Ile177, Gly216, } \\
\text { Gly240 }\end{array}$ & $\begin{array}{l}\text { Lys13, Asn15, Lys68, } \\
\text { Ala73, Lys112, } \\
\text { Trp191, Gly210, } \\
\text { Val212, Gly232 }\end{array}$ & $\begin{array}{l}\text { Mutagen } \\
\text {-Positive } \\
\text {-Negative } \\
\text {-Negative } \\
\text {-Negative } \\
800 \mathrm{mg} / \mathrm{kg}\end{array}$ \\
\hline
\end{tabular}

3.2. Interaction of $T 1-T 5$ and D4 compounds with MtTIM and HsTIM.

To describe the probable interaction between each compound (T1-T5 and D4) with MtTIM and HsTIM, they analyzed the best five conformers from each compound interacting on each TIM (Figure 2, Figure S1 - S6).

A)

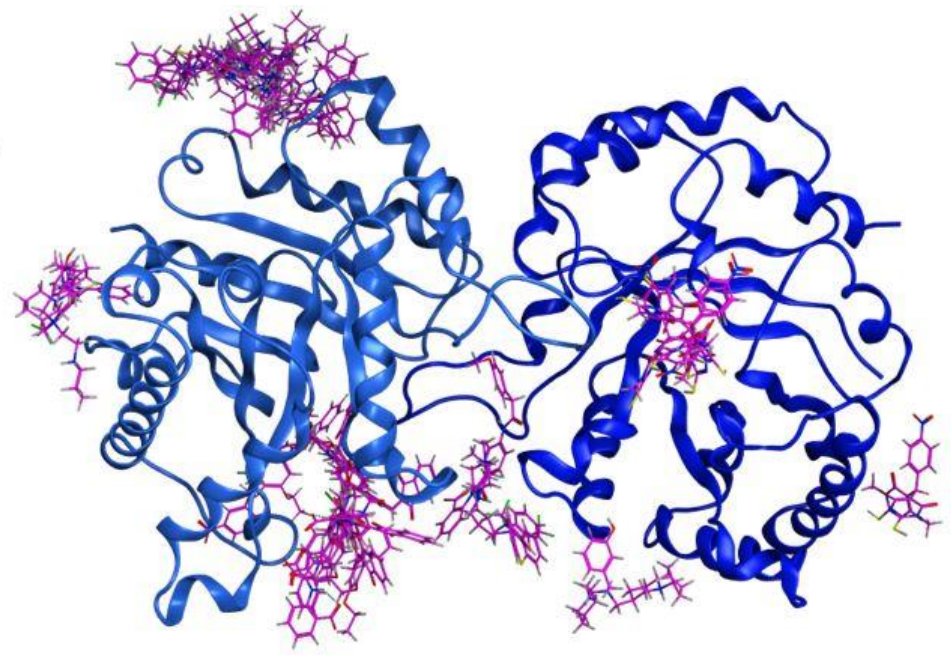

B)

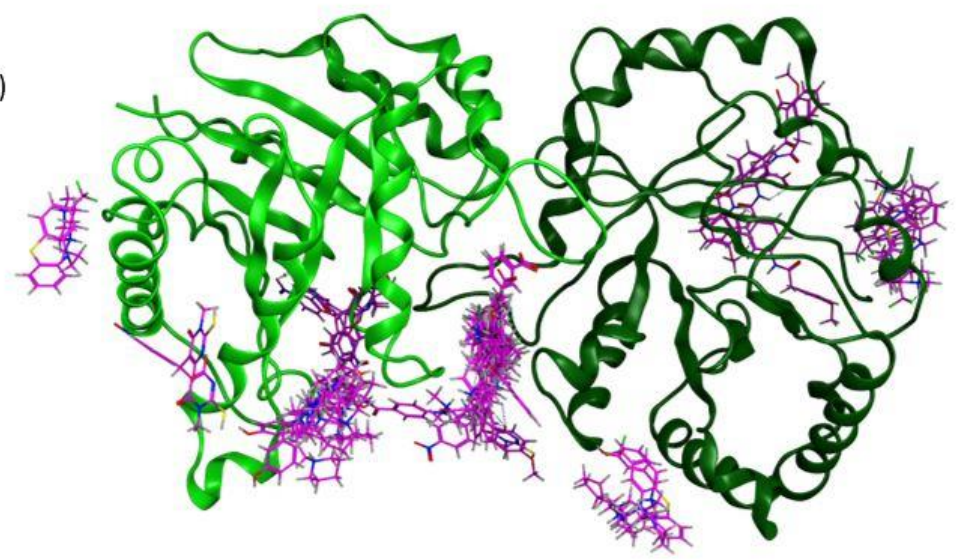

Figure 2. The best five conformers of $\mathrm{T} 1$ - T5 and D4 compounds (Pink); in total 36 conformers are indicated in their interaction site from docking results. A) MtTIM (Blue) and B) HsTIM (Green). 
From molecular docking results (Table S3 - S14), were determined the main amino acids for MtTIM to interact with T1 - T5 and D4 compounds in Lys12, Asn14, Asp33, Arg63, His74, Asp82, Glu102, Arg103, Arg104, Thr105, Tyr106, Glu109, Asp110, Lys117, Leu136, His147, Glu172, Trp175, Ile177, Gly178, Gly180, Gly216, Asp231 and Gly240 amino acids, and Lys5, Lys13, Asn15, Asp36, Lys58, Asn65, Tyr67, Lys68, Ala73, Glu77, Trp90, Arg98, Arg99, Val101, Phe102, Gly103, Glu104, Asp106, Glu107, Lys112, Glu133, Val142, Glu145, Ser158, Glu186, Trp191, Lys193, Gly210, Val212, Gln223, Asp225 and Gly232 amino acids for HsTIM; both TIMs have conserved Lys13, Asn15, Glu97, Arg98, Arg99, Glu104, Lys112, Leu132, Glu166, Trp169, Ile171, Gly172, Gly174, Gly210 and Gly234 amino acids (Figure $3)$; despite it, these compounds have a better average of $\Delta$ Gbinding of interaction in their interaction site (Table 2, Table S1 and S2), particularly a greater interaction with Asp and His amino acids in MtTIM (Figure 3). The details of the interaction for each TIM with conformers of each compound are shown in the supplementary material (Figure S1 - S6).

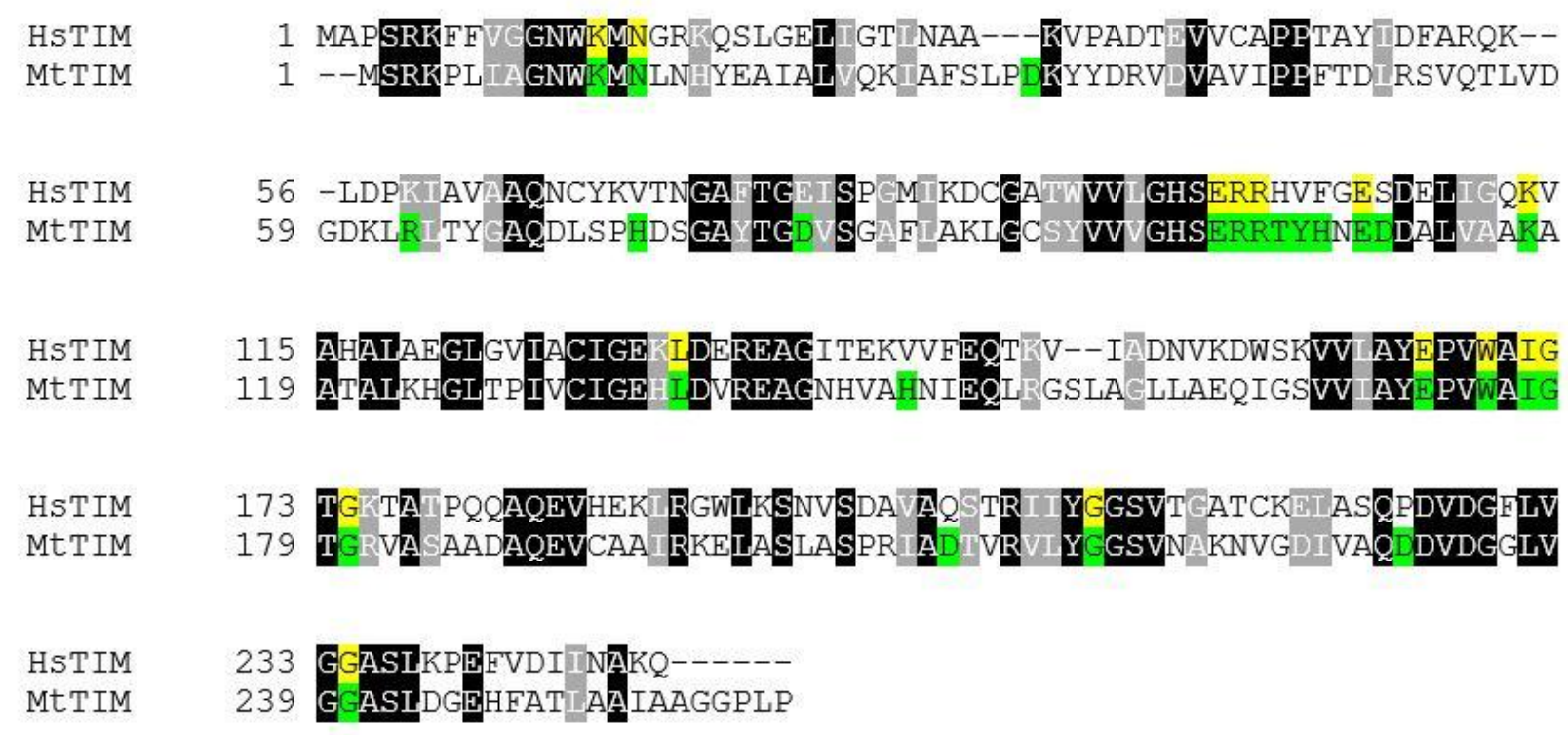

Figure 3. Alignment of HsTIM and MtTIM, with an identity of $36.12 \%$ between both. Black: identical; gray: similar; green: amino acids important for T1-T5 and D4 compounds interacting in MtTIM; yellow: amino acids conserved in HsTIM.

\subsection{Discussion.}

Global efforts continue to develop new drugs for anti-TB due to the increasing factors that favor this disease, such as multidrug-resistant tuberculosis (MDR-TB) and extensively drug-resistant tuberculosis (XDR-TB) [1-4], recently, TB has become more important, since TB as a risk factor for COVID-19 [7, 9-13, 50].

As already mentioned, it is still necessary to develop new drugs anti-TB, here we propose the MtTIM as a therapeutic target, and TIMs from other organisms are being used to develop new drugs, for example, TIM from Trichomonas vaginalis (TvTIM), TIM from Burkholderia thailandensis (BtTIM), TIM from Clostridium perfringens (CpTIM), TIM from Nostoc punctiforme (NpTIM), TIM from Thermus thermophiles (TtTIM), TIM from Streptomyces coelicolor (ScTIM) and TIM from Deinococcus radiodurans (DrTIM) [27, 28]. The MtTIM has characteristics that might help develop a specific TIM inhibitor because there are studies that propose amino acids that are important to generate interactions and selectivity between compounds and TIMs, without affecting the HsTIM [26-29]. 
Moreover, this study proposes compounds that might interact in MtTIM, the molecular docking using against 18 potential sites (Figure 1), and the results indicate the main amino acids in MtTIM for better interaction and selectivity with the compounds selected. Due to more Asp and His in MtTIM, we propose that the interaction with the compounds is better (Figure 3 ). Therefore the averages of $\Delta$ Gbinding are higher in MtTIM (Table 2). For the compounds (T1 - T5 and D4), the main amino acids to interact in MtTIM and HsTIM are indicated in Table 3 and Tables S3 - S14. Despite some amino acids conserved between MtTIM and HsTIM, it is highly probable that the selectivity is only for MtTIM because previously, some of them were tested in HsTIM without effects on its glycolytic activity [26-29]. The analysis of the interactions of conformers of each compound shows the different interactions in the interaction sites between MtTIM and HsTIM (Figure 2, 3, and Table 3).

From docking results, we determine the T1 - T5 and D4 compounds with a better $\Delta$ Gbinding in MtTIM. These compounds interact more Asp, Arg, Lys, and His amino acids in MtTIM than HsTIM (Figure 3, Figure S7 - S12, Table 3 and S3 - S14). It is important to note that MtTIM conserves amino acids that are important in other TIMs (TvTIM, CpTIM, BtTIM, NpTIM, TtTIM, ScTIM, DrTIM, and MtTIM), that are inhibited by compounds interacting with more Asp, Arg, Lys, and His. MtTIM has Asp33, Arg63, His74, Asp82, Thr105, Tyr106, His107, Asp110, His147, Asp209, Asp231 amino acids (Figure 3, Figure S7 - S12), these amino acids with characteristics (positives and negative charges) that increase the interaction with molecules [51], which are important for generating the capacity to interact with the T1 T5 and D4 compounds. Probably these amino acids could help to other compounds to interact with MtTIM. Also, it is important to consider other consequences that some compound/molecule interact with this kind of amino acids, in particular Asp, Arg, and Lys, since these amino acids could influence the conformational stability of the MtTIM [20].

As already mentioned, there are other TIMs with reports of compounds with some inhibitory effect [28]. It is possible to propose to use the compounds against other TIMs, because the MtTIM has a higher percentage of identity with the TIMs tested, the MtTIM has an identity of $42.58 \%$ with BtTIM, $40.23 \%$ with CpTIM, $38.68 \%$ with NpTIM, $64.50 \%$ with ScTIM, $45.59 \%$ with DrRTIM and $49.42 \%$ with TmTIM, and less identity with HsTIM of $36.12 \%$. On the other hand, the Phe46 and Lys230 amino acids are important to decrease the glycolytic activity in the TIMs tested [28], MtTIM has these amino acids, but in HsTIM are not conserved both amino acids (Figure S13). Therefore, the reported compounds could be tested against other TIMs, maintaining the safety of these compounds in the HsTIM, since it has less identity with the TIMs tested.

Currently, there are many developments of anti-tuberculosis drugs that use other therapeutics targets [16-21]. As already mentioned, TIM is growing as a therapeutic target in different organisms, and there are advances in vivo assays, such as D4-compound against $E$. histolytica [29]. Therefore, MtTIM could be another alternative to affect the viability of $M$. tuberculosis, and to be able to contribute to efforts to develop better anti-TB drugs.

\section{Conclusions}

In this study, we propose another therapeutic target against $M$. tuberculosis, the triosephosphate isomerase (MtTIM), because this enzyme has amino acids similar to other TIMs that reduce the enzymatic activity with specific compounds [28, 29] to develop a new drug against $M$. tuberculosis. 
As well, we propose six compounds with high probability to be selective against MtTIM because the main amino acids that are important for interacting in MtTIM are not conserved in HsTIM, these amino acids could generate the selectivity for MtTIM, it was demonstrated in other TIMs by specific compounds [28], these compounds might be tested on MtTIM too. Therefore, future research, such as in vitro and in vivo will be necessary to evaluate this therapeutic target against TB.

\section{Funding}

This research received financial support from NPTC 880-PRODEP-SEP.

\section{Acknowledgments}

The author is very grateful for the support from NPTC 880-PRODEP-SEP, SNI-CONACyT, FMM-UABC, Ricardo Delgadillo Valles, and Dr. José Manuel Avendaño Reyes.

\section{Supplementary Data}

Supporting information includes figures and tables of interactions for compounds with MtTIM, as well as details of the interaction of each compound with MtTIM per amino acid, theoretical toxicity results, ADME characteristics, and physical chemistry, which support the information given in the results and discussion.

\section{Conflicts of Interest}

The authors declare that they have no conflict of interest.

\section{References}

1. Sanou, A.; Bañuls, A-L.; Van Anh, N.T.; Godreuil, S. Mycobacterium tuberculosis: ecology and evolution of a human bacterium. J. Med. Microbiol. 2015, 64, 1261-1269, https://doi.org/10.1099/jmm.0.000171.

2. Koch, A.; Mizrahi, V. Mycobacterium tuberculosis. Trends in Microbiology 2018, 26, 555-556, https://doi.org/10.1016/j.tim.2018.02.012.

3. Araujo, Z.; Macias-Segura, N.; Lopez-Ramos, J.E.; De Waard, J.H.; Vanegas, M.; Patarroyo, M.A.; Salgado, A.; Enciso-Moreno, J.A. Diagnostic accuracy of combinations of serological biomarkers for identifying clinical tuberculosis. J. Infect. Dev. Ctries. 2018, 12, 429-441, https://doi.org/10.3855/jidc.9554.

4. Senghore, M.; Diarra, B. et al. Evolution of Mycobacterium tuberculosis complex lineages and their role in an emerging threat of multidrug resistant tuberculosis in Bamako, Mali. Sci. Rep. 2020, 10, 327, https://doi.org/10.1038/s41598-019-56001-0.

5. CDC. Tratamiento para la enfermedad de tuberculosis Available online: https://www.cdc.gov/tb/esp/topic/treatment/tbdisease.htm.

6. Chetty, S.; Ramesh, M.; Singh-Pillay, A.; Soliman, M.E.S. Recent advancements in the development of antituberculosis drugs. Bioorg. Med. Chem. Lett. 2017, 27, 370-386, https://doi.org/10.1016/j.bmcl.2016.11.084.

7. Chen, Y.; Wang, Y. et al. Active or latent tuberculosis increases susceptibility to COVID-19 and disease severity. medRxiv The preprint server for health sciences 2020, https://doi.org/10.1101/2020.03.10.20033795.

8. Aguilar-León, P.; Cotrina-Castañeda, J.; Zavala-Flores, E. SARS-CoV-2 infection and pulmonary tuberculosis: an analysis of the situation in Peru. Cad. Saude Publica 2020, 36, e00094520, https://doi.org/10.1590/0102-311x00094520.

9. Motta, I.; Centis, R. et al. Tuberculosis, COVID-19 and migrants: Preliminary analysis of deaths occurring in 69 patients from two cohorts. Pulmonology 2020, 26, 233-240, https://doi.org/10.1016/j.pulmoe.2020.05.002.

10. Tadolini, M.; Codecasa, L.R. et al. Active tuberculosis, sequelae and COVID-19 co-infection: first cohort of 49 cases. Eur. Respir. J. 2020, 56, 2001398, https://doi.org/10.1183/13993003.01398-2020.

11. McQuaid, C.F.; McCreesh, N.; Read, J.M.; Sumner, T.; Houben, R.M.G.J.; White, R.G.; Harris, R.C. The potential impact of COVID-19-related disruption on tuberculosis burden. Eur. Respir. J. 2020, 56, 2001718, https://doi.org/10.1183/13993003.01718-2020. 
12. Tapela, K.; Ochieng' Olwal, C.; Quaye, O. Parallels in the pathogenesis of SARS-CoV-2 and M. tuberculosis: a synergistic or antagonistic alliance? Future Microbiol. 2020, 15, 1691-1695, https://doi.org/10.2217/fmb-2020-0179.

13. Chopra, K.K.; Arora, V.K.; Singh, S. COVID 19 and tuberculosis. Indian J. Tuberc. 2020, 67, 149-151, https://doi.org/10.1016/j.ijtb.2020.06.001.

14. Sawicki, R.; Ginalska, G. Mycobacterium tuberculosis topoisomerases and EthR as the targets for new antiTB drugs development. Future Med. Chem. 2019, 11, 2193-2203, https://doi.org/10.4155/fmc-2018-0232.

15. Torfs, E.; Piller, T.; Cos, P.; Cappoen, D. Opportunities for Overcoming Mycobacterium tuberculosis Drug Resistance: Emerging Mycobacterial Targets and Host-Directed Therapy. Int. J. Mol. Sci. 2019, 20, 2868, https://doi.org/10.3390/ijms20122868.

16. Harikishore, A.; Chong, S.S.M.; Ragunathan, P.; Bates, R.W.; Grüber, G. Targeting the menaquinol binding loop of mycobacterial cytochrome bd oxidase. Mol. Divers. 2020, 25, 517-524, https://doi.org/10.1007/s11030-020-10034-0.

17. Santos, P.; Lopez-Vallejo, F.; Ramírez, D.; Caballero, J.; Mata Espinosa, D.; Hernández-Pando, R.; Soto, C.Y. Identification of Mycobacterium tuberculosis $\mathrm{CtpF}$ as a target for designing new antituberculous compounds. Bioorg. Med. Chem. 2020, 28, 115256, https://doi.org/10.1016/j.bmc.2019.115256.

18. Šlachtová, V.; Šebela, M.; Torfs, E.; Oorts, L.; Cappoen, D.; Berka, K.; Bazgier, V.; Brulíková, L. Novel thiazolidinedione-hydroxamates as inhibitors of Mycobacterium tuberculosis virulence factor Zmp1. Eur. J. Med. Chem. 2020, 185, 111812, https://doi.org/10.1016/j.ejmech.2019.111812.

19. Naz, S.; Farooq, U.; Ali, S.; Sarwar, R.; Khan, S.; Abagyan, R. Identification of new benzamide inhibitor against $\alpha$-subunit of tryptophan synthase from Mycobacterium tuberculosis through structure-based virtual screening, anti-tuberculosis activity and molecular dynamics simulations. J. Biomol. Struct. Dyn. 2019, 37, 1043-1053, https://doi.org/10.1080/07391102.2018.1448303.

20. Meuzelaar, H.; Vreede, J.; Woutersen, S. Influence of Glu/Arg, Asp/Arg, and Glu/Lys Salt Bridges on $\alpha$ Helical Stability and Folding Kinetics. Biophys. J. 2016, 110, 2328-2341, https://doi.org/10.1016/j.bpj.2016.04.015.

21. Karale, U.B.; Shinde, A.U.; Babar, D.A.; Sangu, K.G.; Vagolu, S.K.; Eruva, V.K.; Jadav, S.S.; Misra, S.; Dharmarajan, S.; Rode, H.B. 3-Aryl-substituted imidazo[1,2- $\alpha$ ]pyridines as antituberculosis agents. Arch. Pharm. (Weinheim) 2021, https://doi.org/10.1002/ardp.202000419.

22. Jimenez-Sandoval, P.; Vique-Sanchez, J.L. et al. A competent catalytic active site is necessary for substrate induced dimer assembly in triosephosphate isomerase. Biochim. Biophys. Acta - Proteins Proteomics 2017, 1865, 1423-1432 https://doi.org/10.1016/j.bbapap.2017.07.014.

23. Alvarez, G.; Martínez, J.; Aguirre-López, B.; Cabrera, N.; Pérez-Díaz, L.; Gómez-Puyou, M.T. de; GómezPuyou, A.; Pérez-Montfort, R.; Garat, B.; Merlino, A.; Gonzales, M.; Cerecetto, H. New chemotypes as Trypanosoma cruzi triosephosphate isomerase inhibitors: a deeper insight into the mechanism of inhibition. J. Enzyme Inhib. Med. Chem. 2014, 29, 198-204, http://dx.doi.org/10.3109/14756366.2013.765415.

24. Velanker, S.S.; Ray, S.S.; Gokhale, R.S.; Suma, S.; Balaram, H.; Balaram, P.; Murthy, M.R. Triosephosphate isomerase from Plasmodium falciparum: the crystal structure provides insights into antimalarial drug design. Structure 1997, 5, 751-61, https://doi.org/10.1016/s0969-2126(97)00230-X.

25. Minini, L.; Álvarez, G.; González, M.; Cerecetto, H.; Merlino, A. Molecular docking and molecular dynamics simulation studies of Trypanosoma cruzi triosephosphate isomerase inhibitors. Insights into the inhibition mechanism and selectivity. J. Mol. Graph. Model. 2015, 58, 40-9, https://doi.org/10.1016/j.jmgm.2015.02.002.

26. Vique-Sánchez, J.L.; Caro-Gómez, L.A.; Brieba, L.G.; Benítez-Cardoza, C.G. Developing a new drug against trichomoniasis, new inhibitory compounds of the protein triosephosphate isomerase. Parasitol. Int. 2020, 76, 102086, https://doi.org/10.1016/j.parint.2020.102086.

27. Benítez-Cardoza, C.G.; Fernández-Velasco, D.A.; Vique-Sánchez, J.L. Triosephosphate Isomerase Inhibitors as Potential Drugs against Clostridium perfringens. ChemistrySelect 2020, 5, 2365-2370, https://doi.org/10.1002/slct.201904632.

28. Benítez-Cardoza, C.G.; Jiménez-Pineda, A.; Angles-Falconi, S.I.; Fernández-Velasco, D.A.; Vique-Sánchez, J.L. Potential Site to Direct Selective Compounds in the Triosephosphate Isomerase for the Development of New Drugs. ChemistrySelect 2020, 5, 4866-4874, https://doi.org/10.1002/slct.202000820.

29. Vique-Sánchez, J.L.; Jiménez-Pineda, A.; Benítez-Cardoza, C.G. Amoebicidal effect of 5,5'-[(4nitrophenyl)methylene]bis-6-hydroxy-2-mercapto-3-methyl-4(3H)-pyrimidinone), a new drug against Entamoeba histolytica. Arch. Pharm. (Weinheim). 2020, http://dx.doi.org/10.1002/ardp.202000263.

30. Mathur, D.; Malik, G.; Garg, L.C. Biochemical and functional characterization of triosephosphate isomerase from Mycobacterium tuberculosis H37Rv. FEMS Microbiol. Lett. 2006, 263, 229-235, https://doi.org/10.1111/j.1574-6968.2006.00420.x.

31. Connor, S.E.; Capodagli, G.C.; Deaton, M.K.; Pegan, S.D. Structural and functional characterization of Mycobacterium tuberculosis triosephosphate isomerase. Acta Crystallogr. Sect. D Biol. Crystallogr. 2011, 67, 1017-1022, https://doi.org/10.1107/s0907444911042971.

32. Trujillo, C.; Blumenthal, A.; Marrero, J.; Rhee, K.Y.; Schnappinger, D.; Ehrt, S. Triosephosphate Isomerase Is Dispensable In vitro yet Essential for Mycobacterium tuberculosis To Establish Infection. mBio 2014, 5, 
e00085-14, https://doi.org/10.1128/mBio.00085-14.

33. RCSB, Protein Data Bank. Available online: https://www.rcsb.org.

34. Benítez-Cardoza, C.G.; Vique-Sánchez, J.L. Potential inhibitors of the interaction between ACE2 and SARSCoV-2 (RBD), to develop a drug. Life Sci. 2020, 256, 117970, https://doi.org/10.1016/j.lfs.2020.117970.

35. Halgren, T.A. Merck molecular force field. I. Basis, form, scope, parameterization, and performance of MMFF94. J. Comput. Chem. 1996, 17, 490-519, https://doi.org/10.1002/(SICI)1096987X(199604)17:5/6\%3C490::AID-JCC1\%3E3.0.CO;2-P.

36. Vique-Sánchez, J.L. Potential inhibitors interacting in Neuropilin-1 to develop an adjuvant drug against COVID-19, by molecular docking. Bioorg. Med. Chem. 2021, 33, 116040, https://doi.org/10.1016/j.bmc.2021.116040.

37. Del Carpio, C.A.; Takahashi, Y.; Sasaki, S. A new approach to the automatic identification of candidates for ligand receptor sites in proteins: (I) Search for pocket regions. J. Mol. Graph. 1993, 11, 23-29, https://doi.org/10.1016/0263-7855(93)85003-9.

38. Miranker, A.; Karplus, M. Functionality maps of binding sites: A multiple copy simultaneous search method. Proteins Struct. Funct. Bioinform. 1991, 11, 29-34, https://doi.org/10.1002/prot.340110104.

39. Soga, S.; Shirai, H.; Kobori, M.; Hirayama, N. Use of Amino Acid Composition to Predict Ligand-Binding Sites. J. Chem. Inf. Model. 2007, 47, 400-406, https://doi.org/10.1021/ci6002202.

40. Corporation, Hit2Lead.com. Available online: https://www.hit2lead.com/bioactives.asp.

41. Corporation, ChemBridge. Available online: http://www.chembridge.com/screening_libraries.

42. Protein-Ligand Interaction Profiler. Available online: https://plip-tool.biotec.tu-dresden.de/plipweb/plip/index.

43. Salentin, S.; Schreiber, S.; Haupt, V.J.; Adasme, M.F.; Schroeder, M. PLIP: fully automated protein-ligand interaction profiler. Nucleic Acids Res. 2015, 43, W443-W447, https://doi.org/10.1093/nar/gkv315.

44. Labute, P. The generalized Born/volume integral implicit solvent model: estimation of the free energy of hydration using London dispersion instead of atomic surface area. J. Comput. Chem. 2008, 29, 1693-1698, https://doi.org/10.1002/jcc.20933.

45. Wadood, A.; Ghufran, M.; Hassan, S.F.; Khan, H.; Azam, S.S.; Rashid, U. In silico identification of promiscuous scaffolds as potential inhibitors of 1-deoxy- $d$-xylulose 5-phosphate reductoisomerase for treatment of Falciparum malaria. Pharm. Biol. 2017, 55, 19-32, http://dx.doi.org/10.1080/13880209.2016.1225778.

46. PhysChem, ADME \& Toxicity, version 2021.1.1, Advanced Chemistry Development, Inc., Toronto, ON, Canada, 2021, www.acdlabs.com.

47. ADMETlab. Available online: http://admet.scbdd.com/calcpre/index_sys.

48. PreADMET. Available online: https://preadmet.bmdrc.kr/toxicity.

49. ProTox-II - Prediction of Toxicity of Chemicals. Available online: http://tox.charite.de/protox_II/index.php?site=compound_input.

50. Aguilar-León, P.; Cotrina-Castañeda, J.; Zavala-Flores, E. SARS-CoV-2 infection and pulmonary tuberculosis: an analysis of the situation in Peru. Cad. Saude Publica 2020, 36, e00094520, https://doi.org/10.1590/0102-311x00094520.

51. Ellington, A.; Cherry, J.M. Characteristics of Amino Acids. Curr. Protoc. Mol. Biol. 1996, Appendix 1:Appendix 1C, https://doi.org/10.1002/0471142727.mba01cs33. 


\section{Supplementary materials}
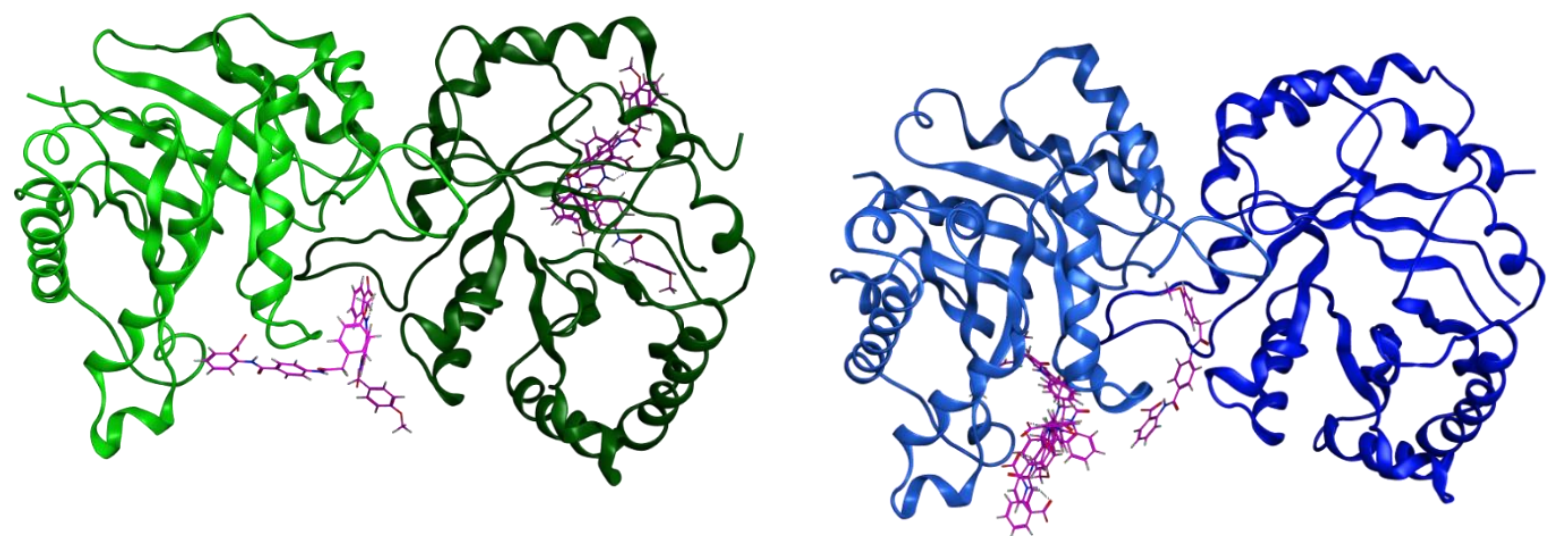

Figure S1. From docking results, the best five conformers of T1 compound (Pink) interacting in MtTIM (Blue) and HsTIM (Green).
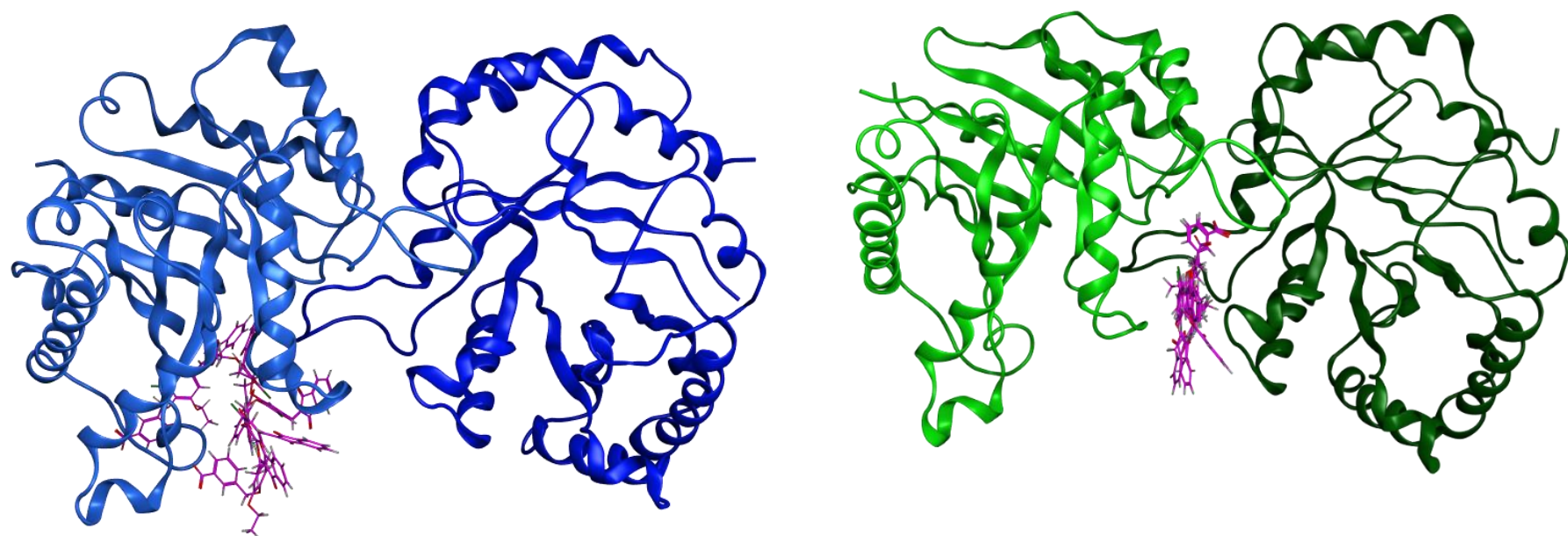

Figure S2. From docking results, the best five conformers of T2 compound (Pink) interacting in MtTIM (Blue) and HsTIM (Green).
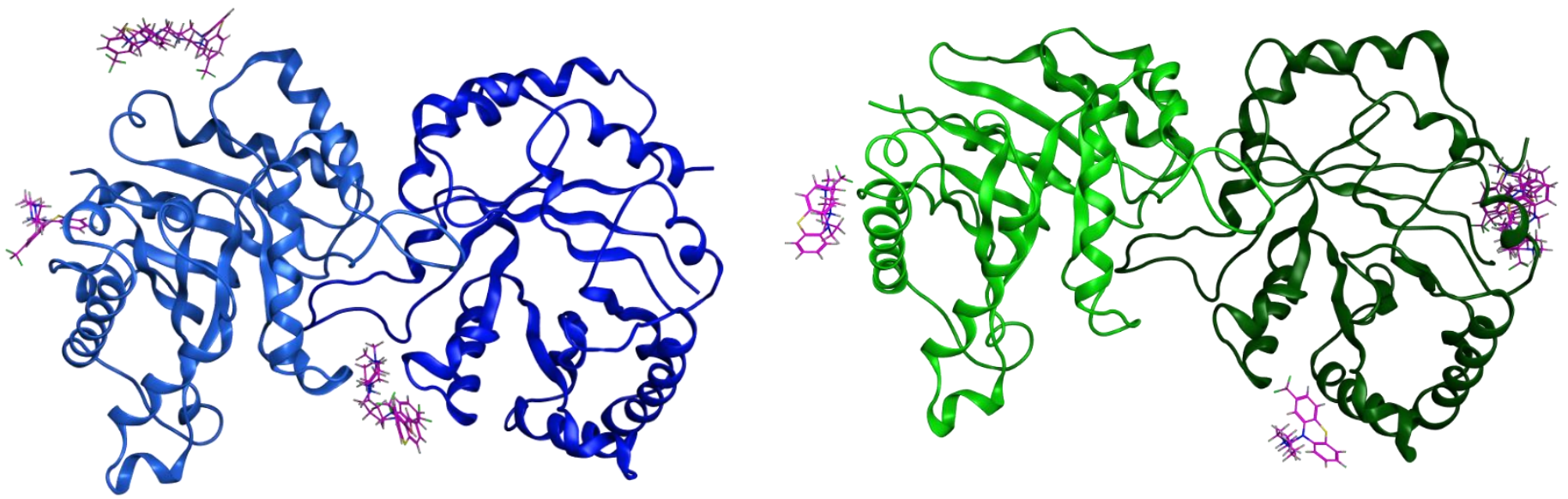

Figure S3. From docking results, the best five conformers of T3 compound (Pink) interacting in MtTIM (Blue) and 

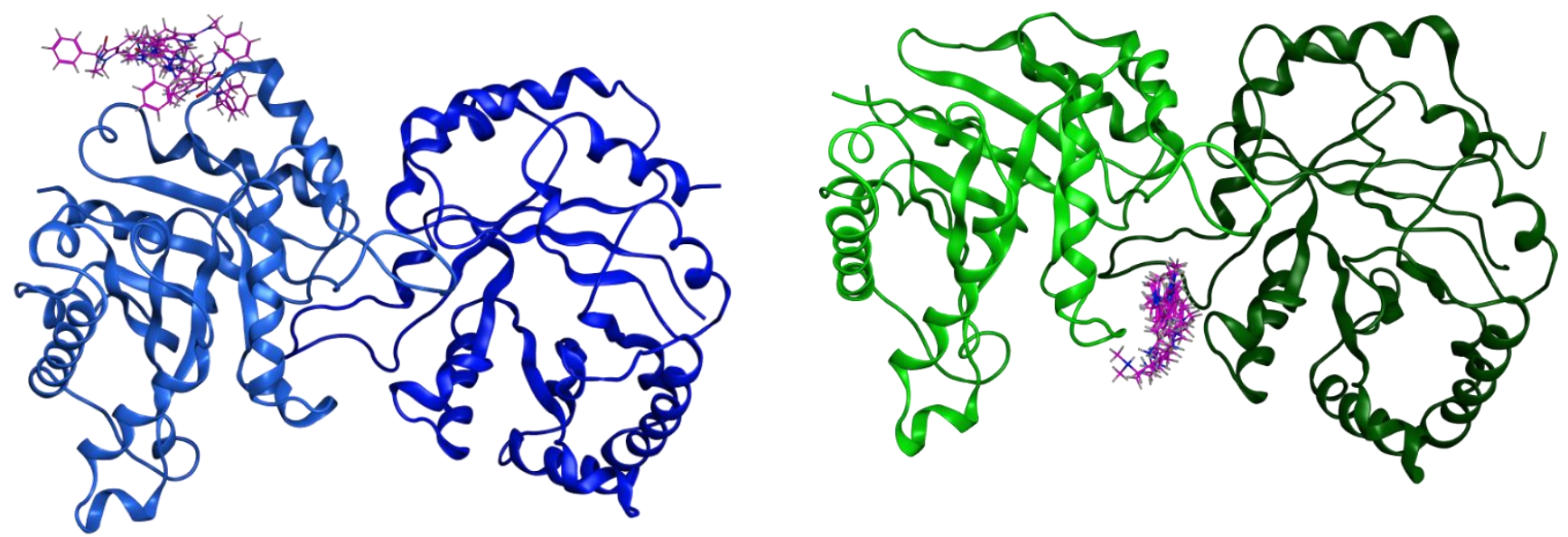

Figure S4. From docking results, the best five conformers of T4 compound (Pink) interacting in MtTIM (Blue) and HsTIM (Green).
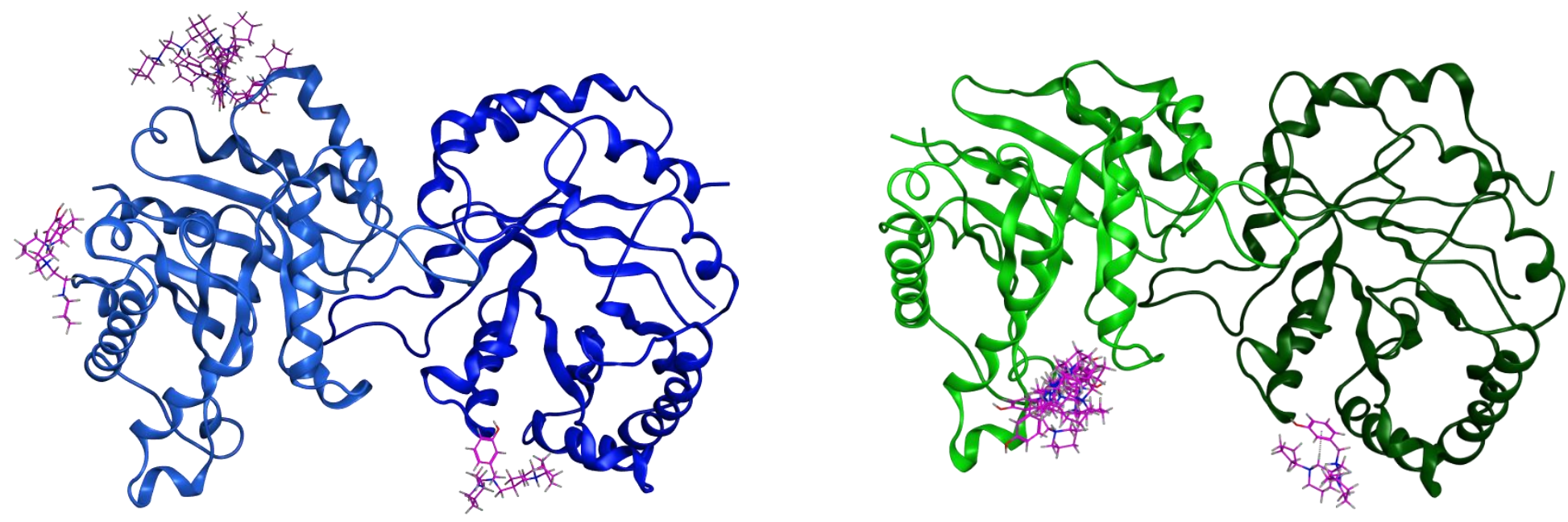

Figure S5. From docking results, the best five conformers of T5 compound (Pink) interacting in MtTIM (Blue) and HsTIM (Green).
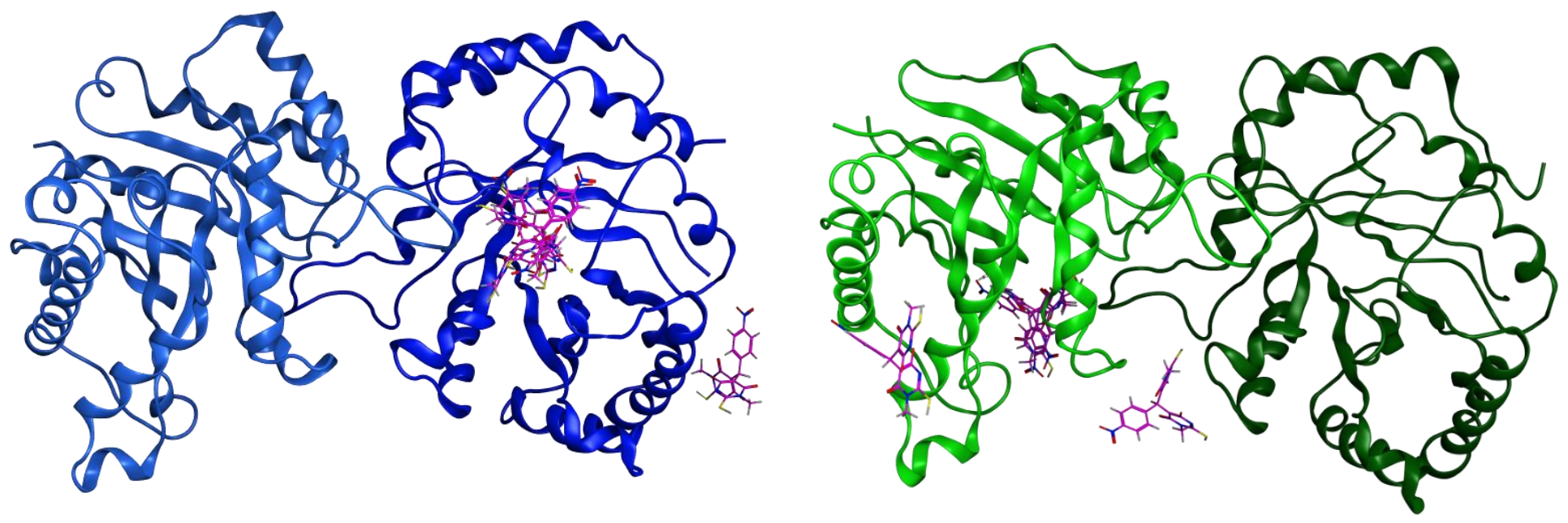

Figure S6. From docking results, the best five conformers of D4 compound (Pink) interacting in MtTIM (Blue) and HsTIM (Green). 


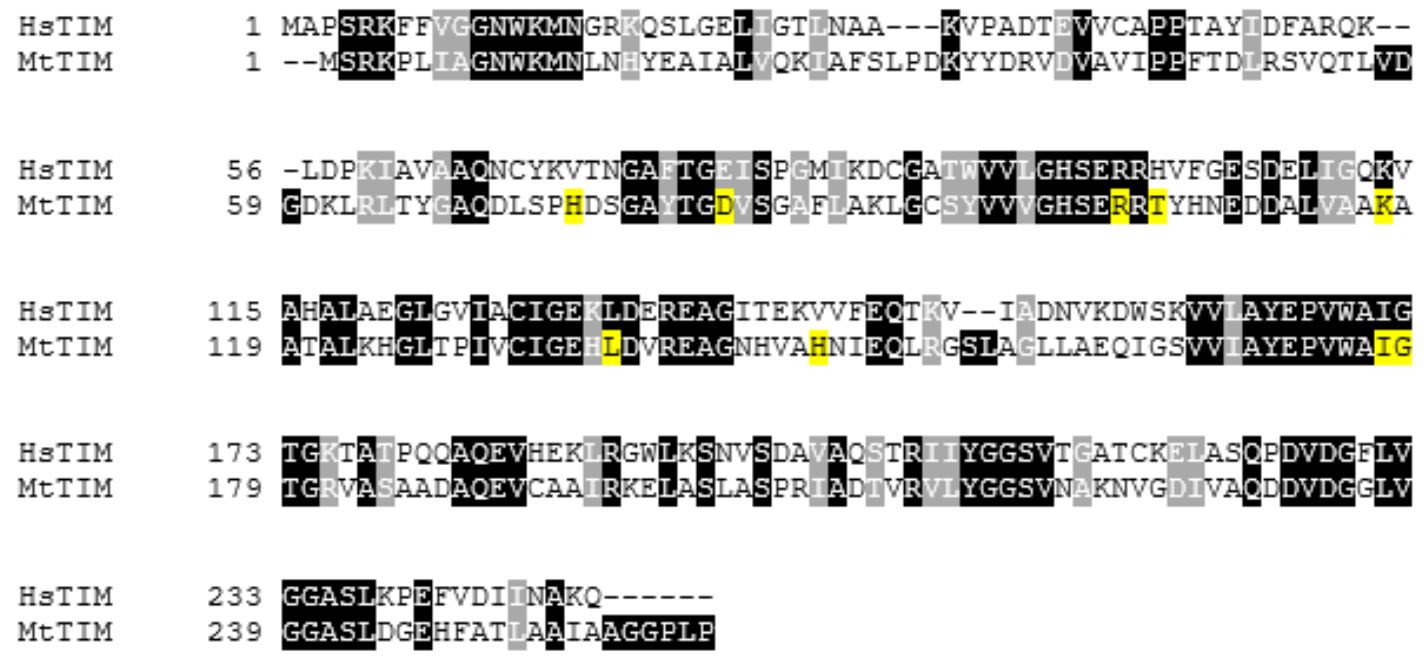

Figure S7. Alignment of HsTIM and MtTIM. Blck: identical; gray: similar; yellow: amino acids important for interaction of T1 compound with MtTIM.

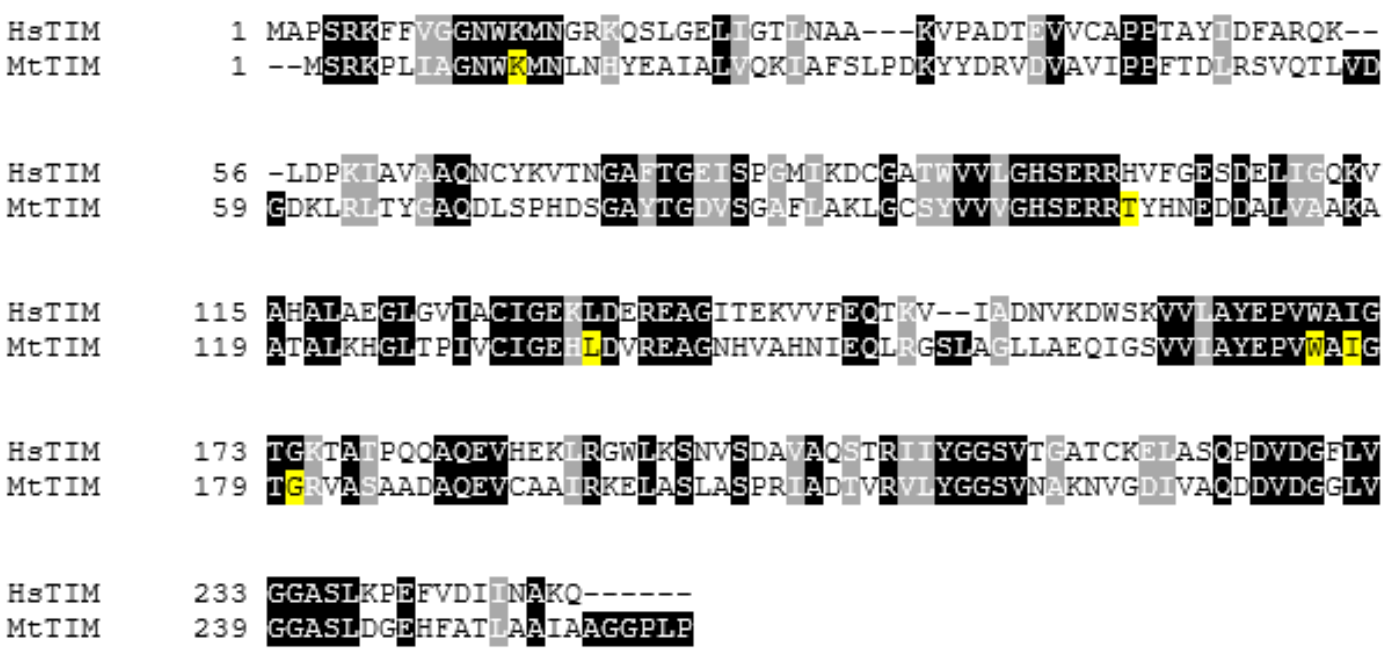

Figure S8. Alignment of HsTIM and MtTIM. Blck: identical; gray: similar; yellow: amino acids important for interaction of T2 compound with MtTIM.

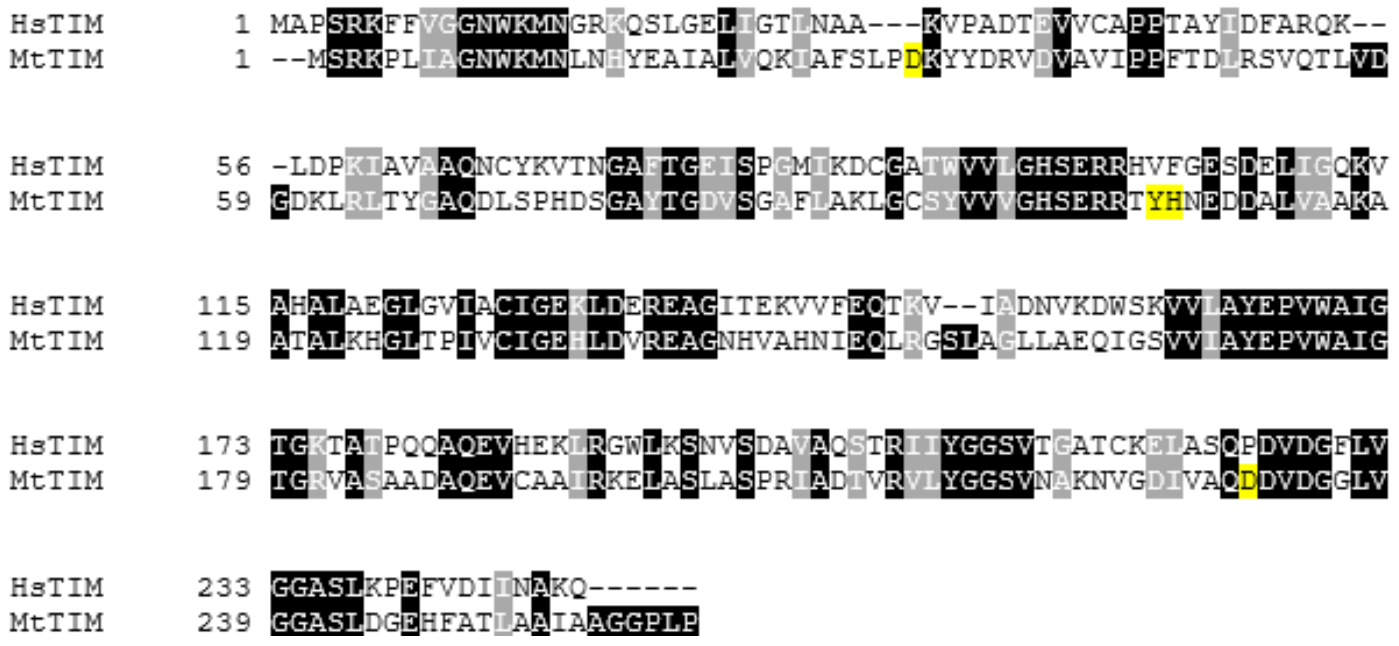

Figure S9. Alignment of HsTIM and MtTIM. Blck: identical; gray: similar; yellow: amino acids important for interaction of T3 compound with MtTIM. 


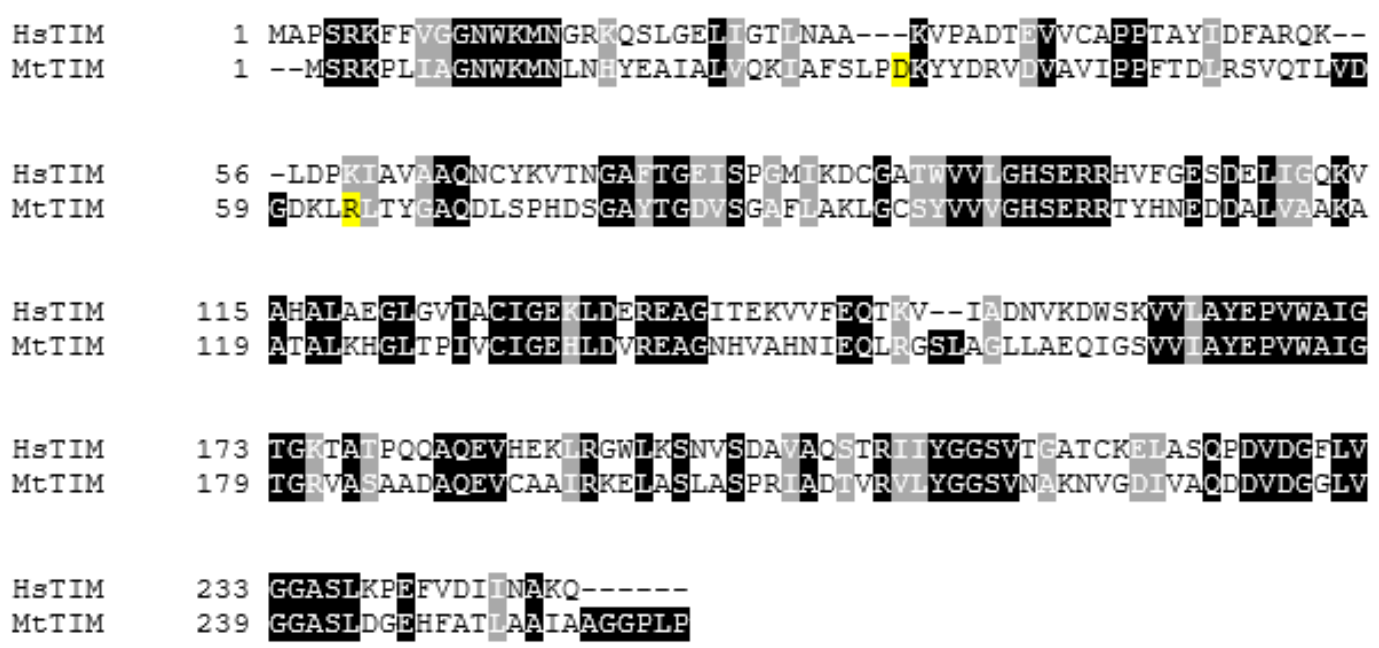

Figure S10. Alignment of HsTIM and MtTIM. Blck: identical; gray: similar; yellow: amino acids important for interaction of T4 compound with MtTIM.

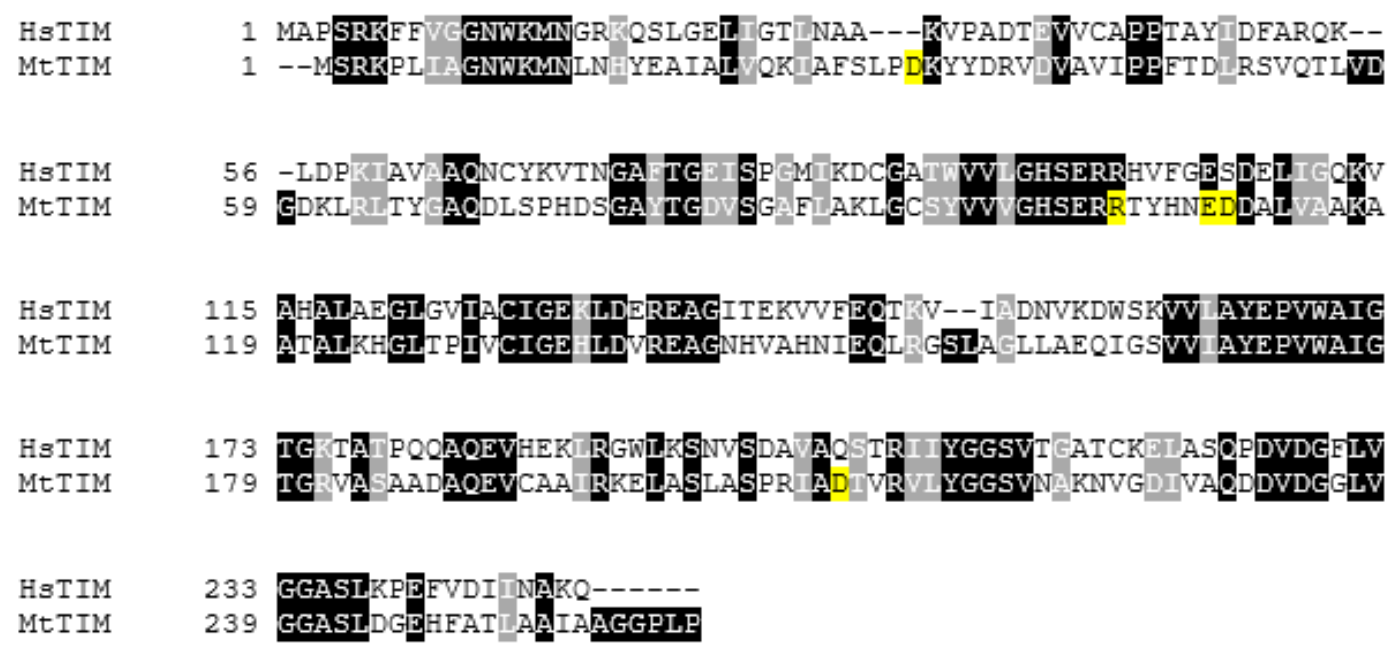

Figure S11. Alignment of HsTIM and MtTIM. Blck: identical; gray: similar; yellow: amino acids important for interaction of T5 compound with MtTIM.

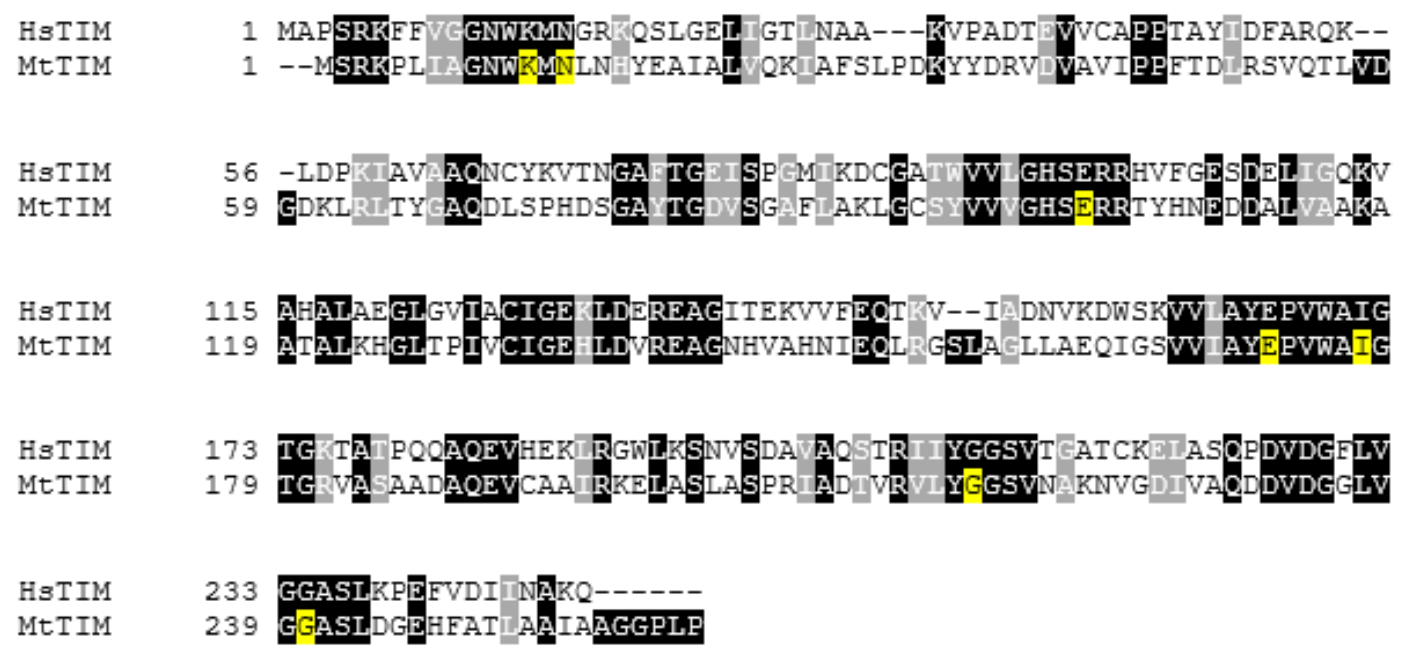

Figure S12. Alignment of HsTIM and MtTIM. Blck: identical; gray: similar; yellow: amino acids important for interaction of D4 compound with MtTIM. 


$\begin{array}{ll}\text { P60174 } & \text { TPIS_HUMAN } \\ \text { P9WG43 } & \text { TPIS-MYCTU } \\ \text { Q2SZN7 } & \text { Q2SZN7 BURTA } \\ \text { Q8XKU1 } & \text { TPIS_CIOPE } \\ \text { B2JA20 } & \text { TPIS_NOSP7 } \\ \text { Q92520 } & \text { TPIS_STRCO } \\ \text { Q9RUP5 } & \text { TPIS_DEIRA } \\ \text { AOAONOZRW5 } & \text { AOAONOZRW5_THESC }\end{array}$

$\begin{array}{ll}\text { P60174 } & \text { TPIS_HUMAN } \\ \text { P9WG43 } & \text { TPIS-MYCTU } \\ \text { Q2SZN7 } & \text { Q2SZN77_BURTA } \\ \text { Q8XKU1 } & \text { TPIS_CLOPE } \\ \text { B2JA20 } & \text { TPIS_NOSP7 } \\ \text { Q92520 } & \text { TPIS-STRCO } \\ \text { Q9RUP5 } & \text { TPIS-DEIRA } \\ \text { AOAONOZRW5 AOAONOZRW5_THESC }\end{array}$

$\begin{array}{lll}\text { P60174 } & \text { TPIS HUMAN } & 114 \\ \text { P9WG43 } & \text { TPIS-MYCTU } & 119 \\ \text { Q2SZN7 } & \text { Q2SZN7 BURTA } & 117 \\ \text { Q8XKU1 } & \text { TPIS_CLOPE } & 112 \\ \text { B2JA20 } & \text { TPIS-NOSP7 } & 11 \\ \text { Q9Z520 } & \text { TPIS-STRCO } & 119 \\ \text { Q9RUP5 } & \text { TPIS-DEIRA } & 111 \\ \text { A RAONOZRN5 } & \text { AOAONOZRW5 }\end{array}$

AOAONOZRW5 AOAONOZRW5_THESC 112

$\begin{array}{lll}\text { P60174 } & \text { TPIS_HUMAN } & 172 \\ \text { P9WG43 } & \text { TPIS-MYCTU } & 178 \\ \text { Q2SZN7 } & \text { Q2SZN77BURTA } & 177 \\ \text { Q8XKU1 } & \text { TPIS_CLOPE } & 172 \\ \text { B2JA20 } & \text { TPIS_NOSP7 } & 171 \\ \text { Q9Z520 } & \text { TPIS-STRCO } & 179 \\ \text { Q9RUP5 } & \text { TPIS-DEIRA } & 167 \\ \text { AOAONOZRW5 } & \text { AOAONOZRW5_THESC } 172\end{array}$

$\begin{array}{lll}\text { P60174 } & \text { TPIS_HUMAN } & 232 \\ \text { P9WG43 } & \text { TPIS-MYCTU } & 238 \\ \text { Q2SZN7 } & \text { Q2SZN7 BURTA } & 233 \\ \text { Q8XKU1 } & \text { TPIS_CLOPE } & 232 \\ \text { B2JA20 } & \text { TPIS_NOSP7 } & 224 \\ \text { Q9Z520 } & \text { TPIS_STRCO } & 239 \\ \text { Q9RUP5 } & \text { TPIS-DEIRA } & 226 \\ \text { AOAONOZRW5 } & \text { AOAONOZRW5_THESC } 232\end{array}$

MAPSRKF FVGGNWKMNGRKQSIGELIGTLNA_AKVPA---DTE-VVCAPPTI Y YDFARQKI

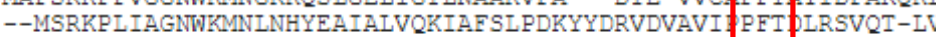
MSKQR IKRVIGNWKMHGRLSGNQALITEVAQGAQAV-HDNVAIGVC P FP ILAQAQA-QI ---MRTPIIAGNWKMHYTIDEAVKLVEELKPLVKDA---KCEVVVC TFV IDAVKK-AV ---MRKTVIAGNWKMFKTOAETOEFLOGFL PHLEETP-OGREVILC PFT DLSVLSK-TI -MTTRT PLMAGNWKMNLNHLEAIAHVOKLAFALADKDYDAVEVAVL AFT DIRSVOT-LV ---MQTLLALNWKMNKT PTEARSWAEELTTKYAPAE--GVDLAVLA PAL DLSALA--AN

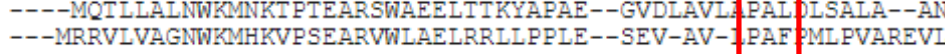
$: \underset{t \rightarrow \neq *}{ }$

D---PKIZVAAONCYKVTNGAFTGEISPGMI KDCGATWVVLGHSERRHVFGESDEIIGQK DGDKLRLTYGAQDLSPHDSGAYTGDVSGAFLAKLGCSYVVVGHSERRTYHNEDDALVAAK DGDKLRLTYGAQDLSPHDSGAYTGDVSGAFLAKLGCSYVVVGHSERRTYHNEDDAVAAK

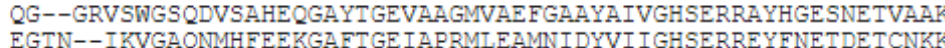
HG--SLIQLGAQNIHWEEFGAYTGEISGPMLTESGVRFVIVGHSERRQYFGETDATVNLR DGDKLKIKYGAQD ISAHDGGAYT GE I SGPMLAKLKCTYVAVGHSERRQYHAETDEIVNAK IP--AGTAFGGODVSAHESGAYTGET SAAMT KDAGA SCVVVGHSERREYHDESDAXVAAK SG--AQVAYGAQDVSPHREGAYTGEVSARMLSDLGCRYTIVGHSERRRYHHETDTLVAEK
$: \quad .^{*}:$

VAHALAEGLGVIACIGEKLDEREAGITEKVVFEQTKVIADN--VKDWSKVVLAYEPVWAI AATALKHGLTPIVCIGEHLDVREAGNHVAHNIEQLRGSLAGLLAEQIGSVVIAYEPVWAI ARRALAAGITPIVCVGETIAFREAGTTEOVVGAOLDAVLAVLSPDFAARIVVAYEPVWAI VKA.FAHNLTP ILCCGETLEQRENGTTNDVIKAQITADLEGLTKEQAEKVVIAYEPIWAI LRTAQRFGLTPILCVGETKQQRDAGETESLIALQLDKGLVDI---DQNNLVIAYEPIWAI VKAAYKHGLTPILCVGEELDVREAGNHVEHTLAQVEGGLKDLAAEQAESVVIAYE PVWAI ARQAOANGLIPIVCVGENLDVRERGEHVPQTLAOLRGSLEGVGA----DVVVAYE PVWAI

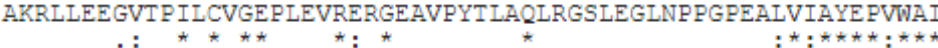

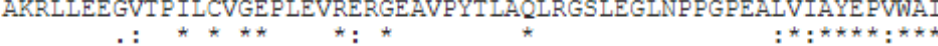

GTGKTATPQQAQEVHEKLRGWLKSNVSDAVAQSTRI IYGGSVTGA CKELASQPDVDGFI GTGRVASAADAQEVCA.AIRKEIASLASPRIADTVRVLYGGSVNAKIVGDIVAQDDVDGGI GTGKSATAEQAQQVHAFLRGRIAAK----GAGHVSLIYGGSV KADI AAEI FGOPDIDGGI GTGKTATSDQANETIAAIRAMVAEMFGQEVA.DKVRIQYGGSV KPN IAEQMAKSDIDGAL GTGETCEAVE ANRI IGITRSOLSGTGKVCGADDAQEVCAAIRGKLAELYSQELADKVRIQYGGSV KSG VAEIMAKPDIDGAT GTGKVCGADDAQEVCAAIRGKLAELYSQELADKVRIQYGGSYKSG VAEIMAKPDIDGAL
GTGKTATADDAEELAAAIRGALREQYGAR-AEGIRVLYGGSVKPE IAEICGKPNVNGAL GTGKTATADDAEELAAAIRGALREQYGAR-AEGIRVLYGGSYKPE IAEICGKPNVNGAI
GTGRNAT PQDAEAMHQAIRQALAELYGEEFARRVRILYGGSYNPK FADLISMPNVDGGI

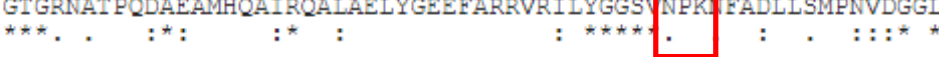

VGGASIKPE-FVDIINAKQ-----

VGGASLDGEHFATLAAIAAGGPLP

IGGASLKSGDFLAICRAAK-----

VGGASLVAADFAQIVNY--------

VGGASLEPESFARIVNFHLV----

VGGASIDSDEFVKIVRFRDQ----

VGGASLKVPDVLGMLDALR-----

VGGASLELESFLALLRIAG-----

Figure S13. Alignment of TIMs (HsTIM, MtTIM, BtTIM, CpTIM, NpTIM, ScTIM, DrTIM and TtTIM) [29]. The red box indicates the position of Phe46 and Lys230 and that HsTIM not have them in its sequence.

Table S1. $\Delta \mathrm{G}_{\text {binding }}$ of 21 to 30 conformers from each compound, average $\Delta \mathrm{G}_{\text {binding }}$ and SD for MtTIM.

\begin{tabular}{|c|c|c|}
\hline Compound & Conformer & $\Delta$ Gbinding $\left(\mathrm{kcal} \mathrm{mol}^{-1}\right)$ \\
\hline $\mathrm{T} 1$ & 1 & -19.348755 \\
\hline T1 & 2 & -11.571745 \\
\hline $\mathrm{T} 1$ & 3 & -9.7634153 \\
\hline $\mathrm{T} 1$ & 4 & -9.736414 \\
\hline $\mathrm{T} 1$ & 5 & -9.7051849 \\
\hline $\mathrm{T} 1$ & 6 & -9.6517811 \\
\hline T1 & 7 & -9.3762941 \\
\hline T1 & 8 & -8.7816877 \\
\hline $\mathrm{T} 1$ & 9 & -8.6600494 \\
\hline $\mathrm{T} 1$ & 10 & -8.5193396 \\
\hline $\mathrm{T} 1$ & 11 & -8.4768028 \\
\hline T1 & 12 & -8.4182835 \\
\hline $\mathrm{T} 1$ & 13 & -7.9478245 \\
\hline $\mathrm{T} 1$ & 14 & -7.7077098 \\
\hline $\mathrm{T} 1$ & 15 & -7.5816722 \\
\hline $\mathrm{T} 1$ & 16 & -7.5145373 \\
\hline $\mathrm{T} 1$ & 17 & -7.3756046 \\
\hline $\mathrm{T} 1$ & 18 & -7.3566918 \\
\hline $\mathrm{T} 1$ & 19 & -7.2295027 \\
\hline $\mathrm{T} 1$ & 20 & -7.1804833 \\
\hline $\mathrm{T} 1$ & 21 & -7.1161585 \\
\hline $\mathrm{T} 1$ & 22 & -6.8189993 \\
\hline $\mathrm{T} 1$ & 23 & -6.4268341 \\
\hline $\mathrm{T} 1$ & 24 & -6.3229618 \\
\hline $\mathrm{T} 1$ & 25 & -6.2017331 \\
\hline $\mathrm{T} 1$ & 26 & -6.1079049 \\
\hline
\end{tabular}




\begin{tabular}{|c|c|c|}
\hline Compound & Conformer & $\Delta$ Gbinding $\left(\mathrm{kcal} \mathrm{mol}^{-1}\right)$ \\
\hline $\mathrm{T} 1$ & 27 & -5.7765675 \\
\hline $\mathrm{T} 1$ & 28 & -5.6680088 \\
\hline $\mathrm{T} 1$ & 29 & -5.6583171 \\
\hline $\mathrm{T} 1$ & 30 & -5.3566537 \\
\hline & & \\
\hline $\mathrm{T} 2$ & 1 & -15.537114 \\
\hline $\mathrm{T} 2$ & 2 & -13.553677 \\
\hline $\mathrm{T} 2$ & 3 & -11.770159 \\
\hline $\mathrm{T} 2$ & 4 & -10.279182 \\
\hline $\mathrm{T} 2$ & 5 & -9.9367619 \\
\hline $\mathrm{T} 2$ & 6 & -9.8412666 \\
\hline $\mathrm{T} 2$ & 7 & -9.2330456 \\
\hline $\mathrm{T} 2$ & 8 & -8.8120222 \\
\hline $\mathrm{T} 2$ & 9 & -7.979362 \\
\hline $\mathrm{T} 2$ & 10 & -7.7080684 \\
\hline $\mathrm{T} 2$ & 11 & -7.6696777 \\
\hline $\mathrm{T} 2$ & 12 & -7.6442399 \\
\hline $\mathrm{T} 2$ & 13 & -7.5763412 \\
\hline $\mathrm{T} 2$ & 14 & -7.4826231 \\
\hline $\mathrm{T} 2$ & 15 & -7.2848735 \\
\hline $\mathrm{T} 2$ & 16 & -7.0824809 \\
\hline $\mathrm{T} 2$ & 17 & -6.7282276 \\
\hline $\mathrm{T} 2$ & 18 & -6.7118812 \\
\hline $\mathrm{T} 2$ & 19 & -6.6992998 \\
\hline $\mathrm{T} 2$ & 20 & -6.6481018 \\
\hline $\mathrm{T} 2$ & 21 & -6.5618019 \\
\hline $\mathrm{T} 2$ & 22 & -6.4962931 \\
\hline $\mathrm{T} 2$ & 23 & -6.4591956 \\
\hline $\mathrm{T} 2$ & 24 & -6.3704786 \\
\hline $\mathrm{T} 2$ & 25 & -6.3360152 \\
\hline $\mathrm{T} 2$ & 26 & -6.3225875 \\
\hline $\mathrm{T} 2$ & 27 & -6.3079095 \\
\hline $\mathrm{T} 2$ & 28 & -6.1934919 \\
\hline $\mathrm{T} 2$ & 29 & -6.1128836 \\
\hline $\mathrm{T} 2$ & 30 & -5.3612046 \\
\hline T3 & 1 & -15.116655 \\
\hline T3 & 2 & -13.008216 \\
\hline T3 & 3 & -7.0577545 \\
\hline T3 & 4 & -7.0203171 \\
\hline T3 & 5 & -6.9499674 \\
\hline T3 & 6 & -6.8818908 \\
\hline T3 & 7 & -6.8359346 \\
\hline T3 & 8 & -6.7382536 \\
\hline T3 & 9 & -6.3743525 \\
\hline T3 & 10 & -6.0799451 \\
\hline T3 & 11 & -6.0681424 \\
\hline T3 & 12 & -6.0644059 \\
\hline T3 & 13 & -5.9516473 \\
\hline T3 & 14 & -5.8327732 \\
\hline T3 & 15 & -5.5505624 \\
\hline T3 & 16 & -5.4287672 \\
\hline T3 & 17 & -5.4237223 \\
\hline T3 & 18 & -5.4153743 \\
\hline $\mathrm{T} 3$ & 19 & -5.2977958 \\
\hline T3 & 20 & -5.0905232 \\
\hline T3 & 21 & -4.6928897 \\
\hline T3 & 22 & -4.2618294 \\
\hline T3 & 23 & -4.1460981 \\
\hline T3 & 24 & -4.1179452 \\
\hline $\mathrm{T} 4$ & 1 & -24.330847 \\
\hline $\mathrm{T} 4$ & 2 & -23.882708 \\
\hline $\mathrm{T} 4$ & 3 & -16.255596 \\
\hline $\mathrm{T} 4$ & 4 & -15.581671 \\
\hline $\mathrm{T} 4$ & 5 & -13.486635 \\
\hline
\end{tabular}




\begin{tabular}{|c|c|c|}
\hline Compound & Conformer & $\Delta$ Gbinding $\left(\mathrm{kcal} \mathrm{mol}^{-1}\right)$ \\
\hline $\mathrm{T} 4$ & 6 & -8.3607273 \\
\hline $\mathrm{T} 4$ & 7 & -7.1885114 \\
\hline $\mathrm{T} 4$ & 8 & -6.9169402 \\
\hline $\mathrm{T} 4$ & 9 & -6.888463 \\
\hline $\mathrm{T} 4$ & 10 & -6.8775702 \\
\hline $\mathrm{T} 4$ & 11 & -6.7225504 \\
\hline $\mathrm{T} 4$ & 12 & -6.651176 \\
\hline $\mathrm{T} 4$ & 13 & -6.648479 \\
\hline $\mathrm{T} 4$ & 14 & -6.5183239 \\
\hline $\mathrm{T} 4$ & 15 & -6.1678424 \\
\hline $\mathrm{T} 4$ & 16 & -5.8116722 \\
\hline $\mathrm{T} 4$ & 17 & -5.6924958 \\
\hline $\mathrm{T} 4$ & 18 & -5.0737009 \\
\hline $\mathrm{T} 4$ & 19 & -4.9741526 \\
\hline $\mathrm{T} 4$ & 20 & -4.9722543 \\
\hline $\mathrm{T} 4$ & 21 & -4.9010634 \\
\hline $\mathrm{T} 4$ & 22 & -4.8302636 \\
\hline $\mathrm{T} 4$ & 23 & -4.7352643 \\
\hline $\mathrm{T} 4$ & 24 & -4.6384964 \\
\hline $\mathrm{T} 4$ & 25 & -3.9685273 \\
\hline $\mathrm{T} 4$ & 26 & -3.8633578 \\
\hline $\mathrm{T} 4$ & 27 & -3.4467297 \\
\hline T5 & 1 & -17.860346 \\
\hline $\mathrm{T} 5$ & 2 & -15.663527 \\
\hline T5 & 3 & -12.467755 \\
\hline T5 & 4 & -6.9478664 \\
\hline T5 & 5 & -6.2957191 \\
\hline T5 & 6 & -5.6617556 \\
\hline T5 & 7 & -5.6608129 \\
\hline T5 & 8 & -5.639112 \\
\hline T5 & 9 & -5.4046063 \\
\hline T5 & 10 & -5.0869069 \\
\hline T5 & 11 & -5.0007954 \\
\hline T5 & 12 & -4.8458681 \\
\hline $\mathrm{T} 5$ & 13 & -4.5041757 \\
\hline T5 & 14 & -4.4739423 \\
\hline T5 & 15 & -4.4557891 \\
\hline $\mathrm{T} 5$ & 16 & -4.3064985 \\
\hline T5 & 17 & -4.2176781 \\
\hline $\mathrm{T} 5$ & 18 & -3.9669673 \\
\hline T5 & 19 & -3.5289178 \\
\hline T5 & 20 & -3.3479142 \\
\hline T5 & 21 & -3.1974645 \\
\hline T5 & 22 & -3.058063 \\
\hline D4 & 1 & -12.990515 \\
\hline D4 & 2 & -12.301793 \\
\hline D4 & 3 & -12.146478 \\
\hline D4 & 4 & -10.714886 \\
\hline D4 & 5 & -10.083652 \\
\hline D4 & 6 & -9.6891546 \\
\hline D4 & 7 & -9.5278368 \\
\hline D4 & 8 & -7.8773251 \\
\hline D4 & 9 & -7.6345749 \\
\hline D4 & 10 & -7.2739491 \\
\hline D4 & 11 & -7.1685681 \\
\hline D4 & 12 & -6.9002981 \\
\hline D4 & 13 & -6.7073278 \\
\hline D4 & 14 & -6.6391988 \\
\hline D4 & 15 & -6.279294 \\
\hline D4 & 16 & -6.0771179 \\
\hline D4 & 17 & -6.0020676 \\
\hline D4 & 18 & -5.822444 \\
\hline D4 & 19 & -5.2859912 \\
\hline D4 & 20 & -4.7035975 \\
\hline
\end{tabular}




\begin{tabular}{c|c|c} 
Compound & Conformer & AGbinding $\left(\mathbf{k c a l ~} \mathbf{~ m o l}^{\mathbf{- 1}}\right)$ \\
\hline D4 & 21 & -4.4125037 \\
\hline & &
\end{tabular}

Table S2. $\Delta \mathrm{G}_{\text {binding }}$ of 25 to 29 conformers from each compound, average $\Delta \mathrm{G}_{\text {binding }}$ and SD for HsTIM.

\begin{tabular}{|c|c|c|}
\hline Compound & Conformer & $\Delta$ Gbinding $\left(\mathrm{kcal} \mathrm{mol}^{-1}\right)$ \\
\hline $\mathrm{T} 1$ & 1 & -7.7168059 \\
\hline $\mathrm{T} 1$ & 2 & -7.360672 \\
\hline $\mathrm{T} 1$ & 3 & -7.2650509 \\
\hline $\mathrm{T} 1$ & 4 & -7.2606478 \\
\hline $\mathrm{T} 1$ & 5 & -7.1813784 \\
\hline $\mathrm{T} 1$ & 6 & -7.179544 \\
\hline $\mathrm{T} 1$ & 7 & -7.0657287 \\
\hline $\mathrm{T} 1$ & 8 & -6.9319258 \\
\hline $\mathrm{T} 1$ & 9 & -6.76088 \\
\hline $\mathrm{T} 1$ & 10 & -6.6002774 \\
\hline $\mathrm{T} 1$ & 11 & -6.5789924 \\
\hline $\mathrm{T} 1$ & 12 & -6.565639 \\
\hline $\mathrm{T} 1$ & 13 & -6.5065255 \\
\hline $\mathrm{T} 1$ & 14 & -6.5045161 \\
\hline $\mathrm{T} 1$ & 15 & -6.4828606 \\
\hline $\mathrm{T} 1$ & 16 & -6.445879 \\
\hline $\mathrm{T} 1$ & 17 & -6.4457469 \\
\hline $\mathrm{T} 1$ & 18 & -6.3822765 \\
\hline $\mathrm{T} 1$ & 19 & -6.3690825 \\
\hline $\mathrm{T} 1$ & 20 & -6.3519197 \\
\hline $\mathrm{T} 1$ & 21 & -6.2274313 \\
\hline $\mathrm{T} 1$ & 22 & -6.1355376 \\
\hline $\mathrm{T} 1$ & 23 & -6.1147327 \\
\hline $\mathrm{T} 1$ & 24 & -6.0977507 \\
\hline $\mathrm{T} 1$ & 25 & -6.0827899 \\
\hline $\mathrm{T} 1$ & 26 & -6.0152578 \\
\hline $\mathrm{T} 1$ & 27 & -5.7975535 \\
\hline $\mathrm{T} 1$ & 28 & -5.7748508 \\
\hline $\mathrm{T} 1$ & 29 & -5.7234125 \\
\hline $\mathrm{T} 2$ & 1 & -7.9971185 \\
\hline $\mathrm{T} 2$ & 2 & -7.7562976 \\
\hline $\mathrm{T} 2$ & 3 & -7.6788526 \\
\hline $\mathrm{T} 2$ & 4 & -7.591114 \\
\hline $\mathrm{T} 2$ & 5 & -7.4447231 \\
\hline $\mathrm{T} 2$ & 6 & -7.3959584 \\
\hline $\mathrm{T} 2$ & 7 & -7.3230925 \\
\hline $\mathrm{T} 2$ & 8 & -7.304625 \\
\hline $\mathrm{T} 2$ & 9 & -7.1931901 \\
\hline $\mathrm{T} 2$ & 10 & -7.0935645 \\
\hline $\mathrm{T} 2$ & 11 & -7.0325017 \\
\hline $\mathrm{T} 2$ & 12 & -6.989707 \\
\hline $\mathrm{T} 2$ & 13 & -6.9020367 \\
\hline $\mathrm{T} 2$ & 14 & -6.8814683 \\
\hline $\mathrm{T} 2$ & 15 & -6.8244319 \\
\hline $\mathrm{T} 2$ & 16 & -6.7677431 \\
\hline $\mathrm{T} 2$ & 17 & -6.7304602 \\
\hline $\mathrm{T} 2$ & 18 & -6.5045209 \\
\hline $\mathrm{T} 2$ & 19 & -6.2630115 \\
\hline $\mathrm{T} 2$ & 20 & -6.0394382 \\
\hline $\mathrm{T} 2$ & 21 & -5.9408007 \\
\hline $\mathrm{T} 2$ & 22 & -5.8978119 \\
\hline $\mathrm{T} 2$ & 23 & -5.887135 \\
\hline $\mathrm{T} 2$ & 24 & -5.8579259 \\
\hline $\mathrm{T} 2$ & 25 & -5.3863916 \\
\hline $\mathrm{T} 2$ & 26 & -5.3284125 \\
\hline $\mathrm{T} 2$ & 27 & -5.2395229 \\
\hline $\mathrm{T} 2$ & 28 & -5.0759993 \\
\hline $\mathrm{T} 2$ & 29 & -2.8577199 \\
\hline T3 & 1 & -6.5749302 \\
\hline
\end{tabular}




\begin{tabular}{|c|c|c|}
\hline Compound & Conformer & $\Delta$ Gbinding $\left(\mathrm{kcal} \mathrm{mol}^{-1}\right)$ \\
\hline T3 & 2 & -6.3824253 \\
\hline T3 & 3 & -6.2241406 \\
\hline T3 & 4 & -6.2208524 \\
\hline T3 & 5 & -6.1575103 \\
\hline T3 & 6 & -5.9685321 \\
\hline T3 & 7 & -5.8002906 \\
\hline T3 & 8 & -5.6772218 \\
\hline T3 & 9 & -5.6754823 \\
\hline T3 & 10 & -5.6222467 \\
\hline T3 & 11 & -5.5276299 \\
\hline T3 & 12 & -5.4636011 \\
\hline T3 & 13 & -5.4501634 \\
\hline T3 & 14 & -5.3239136 \\
\hline T3 & 15 & -5.2912912 \\
\hline $\mathrm{T} 3$ & 16 & -5.26686 \\
\hline T3 & 17 & -5.2463126 \\
\hline T3 & 18 & -5.2417669 \\
\hline $\mathrm{T} 3$ & 19 & -5.226068 \\
\hline T3 & 20 & -5.2058945 \\
\hline T3 & 21 & -5.172924 \\
\hline T3 & 22 & -5.0544639 \\
\hline T3 & 23 & -4.6577363 \\
\hline T3 & 24 & -4.6173983 \\
\hline T3 & 25 & -4.4684453 \\
\hline T3 & 26 & -4.3001547 \\
\hline T3 & 27 & -4.2011528 \\
\hline $\mathrm{T} 4$ & 1 & -8.3689117 \\
\hline $\mathrm{T} 4$ & 2 & -8.1757193 \\
\hline $\mathrm{T} 4$ & 3 & -7.764658 \\
\hline $\mathrm{T} 4$ & 4 & -7.6395993 \\
\hline $\mathrm{T} 4$ & 5 & -7.582962 \\
\hline $\mathrm{T} 4$ & 6 & -7.4218984 \\
\hline $\mathrm{T} 4$ & 7 & -7.0887237 \\
\hline $\mathrm{T} 4$ & 8 & -6.987906 \\
\hline $\mathrm{T} 4$ & 9 & -6.8171511 \\
\hline $\mathrm{T} 4$ & 10 & -6.7192264 \\
\hline $\mathrm{T} 4$ & 11 & -6.6646791 \\
\hline $\mathrm{T} 4$ & 12 & -6.561758 \\
\hline $\mathrm{T} 4$ & 13 & -6.5300455 \\
\hline $\mathrm{T} 4$ & 14 & -6.3378372 \\
\hline $\mathrm{T} 4$ & 15 & -6.3233337 \\
\hline $\mathrm{T} 4$ & 16 & -6.2640481 \\
\hline $\mathrm{T} 4$ & 17 & -6.181746 \\
\hline $\mathrm{T} 4$ & 18 & -6.1525826 \\
\hline $\mathrm{T} 4$ & 19 & -6.0715342 \\
\hline $\mathrm{T} 4$ & 20 & -5.7689247 \\
\hline $\mathrm{T} 4$ & 21 & -5.7037458 \\
\hline $\mathrm{T} 4$ & 22 & -5.5879264 \\
\hline $\mathrm{T} 4$ & 23 & -5.5096035 \\
\hline $\mathrm{T} 4$ & 24 & -5.4134665 \\
\hline $\mathrm{T} 4$ & 25 & -5.3651433 \\
\hline $\mathrm{T} 4$ & 26 & -4.5676293 \\
\hline $\mathrm{T} 4$ & 27 & -4.4412456 \\
\hline $\mathrm{T} 4$ & 28 & -4.4044247 \\
\hline $\mathrm{T} 4$ & 29 & -3.9639657 \\
\hline $\mathrm{T} 4$ & 30 & -3.6974566 \\
\hline T5 & 1 & -6.8720546 \\
\hline T5 & 2 & -6.8253832 \\
\hline T5 & 3 & -6.7739153 \\
\hline T5 & 4 & -6.5734506 \\
\hline T5 & 5 & -6.5388331 \\
\hline T5 & 6 & -6.4891763 \\
\hline T5 & 7 & -6.4298067 \\
\hline $\mathrm{T} 5$ & 8 & -6.3848505 \\
\hline
\end{tabular}




\begin{tabular}{|c|c|c|}
\hline Compound & Conformer & $\Delta$ Gbinding $\left(\mathrm{kcal} \mathrm{mol}^{-1}\right)$ \\
\hline T5 & 9 & -6.3394074 \\
\hline T5 & 10 & -6.2334661 \\
\hline T5 & 11 & -6.131846 \\
\hline T5 & 12 & -5.9663172 \\
\hline T5 & 13 & -5.9041052 \\
\hline T5 & 14 & -5.8545771 \\
\hline T5 & 15 & -5.8322792 \\
\hline T5 & 16 & -5.5169511 \\
\hline T5 & 17 & -5.4954123 \\
\hline T5 & 18 & -5.4517694 \\
\hline T5 & 19 & -5.3147964 \\
\hline T5 & 20 & -5.2868881 \\
\hline T5 & 21 & -5.2818365 \\
\hline $\mathrm{T} 5$ & 22 & -5.237505 \\
\hline T5 & 23 & -5.1515322 \\
\hline T5 & 24 & -5.1090546 \\
\hline T5 & 25 & -5.0306735 \\
\hline T5 & 26 & -5.0156164 \\
\hline T5 & 27 & -4.693058 \\
\hline T5 & 28 & -4.6785226 \\
\hline T5 & 29 & -4.4189272 \\
\hline D4 & 1 & -7.9663849 \\
\hline D4 & 2 & -7.0733962 \\
\hline D4 & 3 & -6.6277122 \\
\hline D4 & 4 & -6.2691174 \\
\hline D4 & 5 & -6.2620864 \\
\hline D4 & 6 & -6.2564354 \\
\hline D4 & 7 & -6.1517792 \\
\hline D4 & 8 & -6.1448488 \\
\hline D4 & 9 & -6.1111188 \\
\hline D4 & 10 & -6.0154591 \\
\hline D4 & 11 & -5.7929511 \\
\hline D4 & 12 & -5.6190715 \\
\hline D4 & 13 & -5.570888 \\
\hline D4 & 14 & -5.4607539 \\
\hline D4 & 15 & -5.3625689 \\
\hline D4 & 16 & -5.3184571 \\
\hline D4 & 17 & -5.311152 \\
\hline D4 & 18 & -5.297945 \\
\hline D4 & 19 & -5.1712837 \\
\hline D4 & 20 & -5.1551957 \\
\hline D4 & 21 & -4.9263911 \\
\hline D4 & 22 & -4.856832 \\
\hline D4 & 23 & -4.7874279 \\
\hline D4 & 24 & -4.7247987 \\
\hline D4 & 25 & -4.7180524 \\
\hline
\end{tabular}

Table S3. Interaction report of each conformer of T1 compound. Number of conformer, Atom of compound, Amino acid in MtTIM, Type of interaction and Distance in angstroms.

\begin{tabular}{c|l|c|c|c|c} 
Conformer & Ligand & \multicolumn{2}{|c|}{ Residues in MtTIM } & Interaction & Distance \\
\hline 1 & O & LEU & 136 & H-acceptor & 2.98 \\
\hline & 6-ring & ILE & 177 & pi-H & 4.49 \\
\hline 2 & 6-ring & THR & 105 & pi-H & 3.67 \\
\hline 3 & O & LEU & 136 & H-acceptor & 3.43 \\
\hline 4 & O & HIS & 147 & H-acceptor & 3.22 \\
\hline & 6-ring & GLY & 178 & pi-H & 4.02 \\
\hline 5 & N & ASP & 82 & H-donor & 2.78 \\
\hline & O & HIS & 74 & H-acceptor & 3.07 \\
\hline & O & LYS & 117 & H-acceptor & 2.77 \\
\hline & 6-ring & ARG & 103 & pi-cation & 4.66
\end{tabular}


Table S4. Interaction report of each conformer of T2 compound. Number of conformer, Atom of compound,

Amino acid in MtTIM, Type of interaction and Distance in angstroms.

\begin{tabular}{c|l|c|r|c|c} 
Conformer & Ligand & \multicolumn{2}{|c|}{ Residues in MtTIM } & Interaction & Distance \\
\hline 1 & O & LEU & 136 & H-acceptor & 3.45 \\
\hline & O & LEU & 136 & H-acceptor & 3.25 \\
\hline & O & TRP & 175 & H-acceptor & 3.38 \\
\hline 2 & CL & THR & 105 & H-donor & 3.12 \\
\hline 3 & O & LYS & 12 & H-acceptor & 3.17 \\
\hline & 6-ring & ILE & 177 & pi-H & 4.11 \\
\hline & 6-ring & GLY & 180 & pi-H & 3.52
\end{tabular}

Table S5. Interaction report of each conformer of T3 compound. Number of conformer, Atom of compound, Amino acid in MtTIM, Type of interaction and Distance in angstroms.

\begin{tabular}{c|l|c|c|c|c} 
Conformer & Ligand & \multicolumn{2}{|c|}{ Residues in MtTIM } & Interaction & Distance \\
\hline 1 & C & ASP & 33 & H-donor & 3.64 \\
\hline 2 & N & ASP & 33 & H-donor & 3 \\
\hline & C & ASP & 33 & H-donor & 3.32 \\
\hline & N & ASP & 33 & ionic & 3 \\
\hline & N & ASP & 33 & ionic & 3.75 \\
\hline 3 & C & ASP & 231 & H-donor & 3.37 \\
\hline 4 & C & TYR & 106 & H-pi & 4.27 \\
\hline 5 & C & TYR & 106 & H-pi & 4.9 \\
\hline & C & HIS & 107 & H-pi & 4.64
\end{tabular}

Table S6. Interaction report of each conformer of T4 compound. Number of conformer, Atom of compound,

Amino acid in MtTIM, Type of interaction and Distance in angstroms.

\begin{tabular}{c|l|c|c|c|c} 
Conformer & Ligand & \multicolumn{2}{|c|}{ Residues in MtTIM } & Interaction & Distance \\
\hline 1 & N & ASP & 33 & H-donor & 2.74 \\
\hline & N & ASP & 33 & H-donor & 2.99 \\
\hline & N & ASP & 33 & ionic & 2.74 \\
\hline & N & ASP & 33 & ionic & 2.99 \\
\hline & N & ASP & 33 & H-donor & 2.88 \\
\hline & N & ASP & 33 & H-donor & 3.35 \\
\hline & N & ASP & 33 & ionic & 2.88 \\
\hline & N & ASP & 33 & ionic & 3.35 \\
\hline & N & ASP & 33 & H-donor & 2.7 \\
\hline & N & ASP & 33 & ionic & 3 \\
\hline & N & ASP & 33 & ionic & 2.7 \\
\hline & N & ASP & 33 & ionic & 2.87 \\
\hline & N & ASP & 33 & ionic & 3.38 \\
\hline & 6 -ring & ARG & 63 & pi-cation & 3.86 \\
\hline & N & ASP & 33 & H-donor & 2.74 \\
\hline & N & ASP & 33 & ionic & 2.74 \\
\hline & N & ASP & 33 & ionic & 3.82
\end{tabular}

Table S7. Interaction report of each conformer of T5 compound. Number of conformer, Atom of compound, Amino acid in MtTIM, Type of interaction and Distance in angstroms.

\begin{tabular}{c|l|c|c|c|c} 
Conformer & Ligand & \multicolumn{2}{|c|}{ Residues in MtTIM } & Interaction & Distance \\
\hline 1 & N & ASP & 33 & ionic & 3.63 \\
\hline 2 & N & ASP & 33 & H-donor & 2.81 \\
\hline & C & ASP & 33 & H-donor & 3.37 \\
\hline & N & ASP & 33 & ionic & 2.81 \\
\hline 3 & N & ASP & 209 & H-donor & 3.28 \\
\hline & N & ASP & 209 & ionic & 3.98 \\
\hline & N & ASP & 209 & ionic & 3.28 \\
\hline 4 & O & GLU & 109 & H-donor & 3.24 \\
\hline & O & ARG & 104 & H-acceptor & 3.24 \\
\hline & N & ASP & 110 & ionic & 3.66
\end{tabular}


Table S8. Interaction report of each conformer of D4 compound. Number of conformer, Atom of compound, Amino acid in MtTIM, Type of interaction and Distance in angstroms.

\begin{tabular}{c|l|c|c|c|c} 
Conformer & Ligand & \multicolumn{2}{|c}{ Residues in MtTIM } & Interaction & Distance \\
\hline 1 & S & GLU & 172 & H-donor & 2.95 \\
\hline & O & LYS & 12 & H-acceptor & 2.94 \\
\hline & O & LYS & 12 & ionic & 2.94 \\
\hline & O & LYS & 12 & H-acceptor & 2.91 \\
\hline & O & LYS & 12 & ionic & 2.91 \\
\hline & 6-ring & GLY & 240 & pi-H & 3.55 \\
\hline & S & GLU & 172 & H-donor & 3.46 \\
\hline & S & GLY & 216 & H-donor & 3.2 \\
\hline & S & ASN & 14 & H-donor & 3.79 \\
\hline & O & GLY & 240 & H-acceptor & 2.96 \\
\hline & S & GLU & 102 & H-donor & 3.91 \\
\hline & O & LYS & 12 & H-acceptor & 2.89 \\
\hline & O & LYS & 12 & ionic & 2.89 \\
\hline & 6-ring & ILE & 177 & pi-H & 4.46
\end{tabular}

Table S9. Interaction report of each conformer of $\mathrm{T} 1$ compound. Number of conformer, Atom of compound, Amino acid in HsTIM, Type of interaction and Distance in angstroms.

\begin{tabular}{c|l|c|c|c|c} 
Conformer & Ligand & \multicolumn{2}{c}{ Residues in HsTIM } & Interaction & Distance \\
\hline 1 & N & LYS & 58 & H-donor & 3.06 \\
\hline & O & TRP & 90 & H-acceptor & 2.96 \\
\hline & O & LYS & 5 & H-acceptor & 3.19 \\
\hline & N & SER & 158 & H-donor & 3.28 \\
\hline & O & LYS & 5 & H-acceptor & 2.9 \\
\hline & O & LYS & 5 & ionic & 2.9 \\
\hline & O & LYS & 5 & ionic & 2.98 \\
\hline & O & TRP & 90 & H-acceptor & 3.03 \\
\hline & O & ARG & 98 & H-acceptor & 2.96 \\
\hline 4 & O & ARG & 98 & H-acceptor & 3.27 \\
\hline & O & ARG & 98 & H-acceptor & 3.07 \\
\hline & O & ARG & 98 & ionic & 2.96 \\
\hline & O & ARG & 98 & ionic & 3.27 \\
\hline & O & ARG & 98 & ionic & 3.07 \\
\hline & O & ARG & 98 & ionic & 3.82 \\
\hline & O & ARG & 98 & ionic & 3.63 \\
\hline & O & ASP & 106 & H-acceptor & 3.52 \\
\hline & O & ARG & 99 & ionic & 2.87
\end{tabular}

Table S10. Interaction report of each conformer of T2 compound. Number of conformer, Atom of compound, Amino acid in HsTIM, Type of interaction and Distance in angstroms.

\begin{tabular}{c|l|c|c|c|c} 
Conformer & Ligand & \multicolumn{2}{|c|}{ Residues in AXL } & Interaction & Distance \\
\hline 1 & CL & GLU & 77 & H-donor & 3.66 \\
\hline & O & ARG & 98 & H-acceptor & 2.88 \\
\hline & O & ARG & 98 & ionic & 2.88 \\
\hline & O & ARG & 98 & ionic & 3.99 \\
\hline 2 & O & ASN & 65 & H-acceptor & 3.39 \\
\hline 3 & O & TYR & 67 & H-acceptor & 3.3 \\
\hline 4 & CL & GLU & 77 & H-donor & 3.05 \\
\hline & O & ASN & 65 & H-acceptor & 3.4
\end{tabular}

Table S11. Interaction report of each conformer of T3 compound. Number of conformer, Atom of compound, Amino acid in HsTIM, Type of interaction and Distance in angstroms.

\begin{tabular}{c|l|c|c|c|c} 
Conformer & Ligand & \multicolumn{2}{c}{ Residues in HsTIM } & Interaction & Distance \\
\hline 1 & C & GLN & 223 & H-donor & 3.33 \\
\hline 2 & S & ASP & 36 & H-donor & 3.18 \\
\hline & 6-ring & ASP & 36 & pi-H & 4.73 \\
\hline 3 & C & ASP & 225 & H-donor & 3.49 \\
\hline & C & ASP & 225 & H-donor & 3.45 \\
\hline & C & GLU & 186 & H-donor & 3.49 \\
\hline & N & ASP & 225 & ionic & 3.79 \\
\hline & N & ASP & 225 & ionic & 3.67 \\
\hline & 6-ring & LYS & 193 & pi-cation & 3.96
\end{tabular}




\begin{tabular}{c|l|c|r|c|c} 
Conformer & Ligand & \multicolumn{2}{|c}{ Residues in HsTIM } & Interaction & Distance \\
\hline & 6-ring & LYS & 193 & pi-cation & 4.35 \\
\hline & S & GLU & 145 & H-donor & 3.47 \\
\hline & N & GLU & 145 & H-donor & 2.8 \\
\hline & C & GLU & 107 & H-donor & 3.35 \\
\hline & N & GLU & 145 & ionic & 3.86 \\
\hline & N & GLU & 107 & ionic & 3.99 \\
\hline & N & GLU & 145 & ionic & 2.8 \\
\hline & 6-ring & VAL & 142 & pi-H & 4.56 \\
\hline & N & ASP & 36 & H-donor & 2.78 \\
\hline & N & ASP & 36 & ionic & 3.99 \\
\hline & N & ASP & 36 & ionic & 2.78
\end{tabular}

Table S12. Interaction report of each conformer of T4 compound. Number of conformer, Atom of compound, Amino acid in HsTIM, Type of interaction and Distance in angstroms.

\begin{tabular}{c|l|c|c|c|c} 
Conformer & Ligand & \multicolumn{2}{c}{ Residues in HsTIM } & Interaction & Distance \\
\hline 1 & N & VAL & 101 & H-donor & 3.02 \\
\hline & C & GLY & 103 & H-donor & 3.46 \\
\hline & 5 -ring & ARG & 98 & pi-cation & 4.01 \\
\hline & 5 -ring & ARG & 98 & pi-cation & 4.05 \\
\hline & N & GLY & 103 & H-donor & 3.18 \\
\hline & N & VAL & 101 & H-donor & 3.16 \\
\hline & N & ARG & 98 & H-acceptor & 3.21 \\
\hline & 5 -ring & ARG & 98 & pi-cation & 4.42 \\
\hline & N & VAL & 101 & H-donor & 2.93 \\
\hline & C & GLY & 103 & H-donor & 3.46 \\
\hline & $5-$-ring & ARG & 98 & pi-cation & 4.15 \\
\hline & C & VAL & 101 & H-donor & 3.33 \\
\hline & N & ARG & 98 & H-acceptor & 3.08 \\
\hline & $5-$-ring & ARG & 98 & pi-cation & 4.31
\end{tabular}

Table S13. Interaction report of each conformer of T5 compound. Number of conformer, Atom of compound, Amino acid in HsTIM, Type of interaction and Distance in angstroms.

\begin{tabular}{c|l|c|r|c|c} 
Conformer & Ligand & \multicolumn{2}{|c}{ Residues in HsTIM } & Interaction & Distance \\
\hline 1 & N & GLU & 133 & H-donor & 2.83 \\
\hline & C & ASP & 106 & H-donor & 3.5 \\
\hline & C & ASP & 106 & H-donor & 3.49 \\
\hline & N & ASP & 106 & ionic & 3.94 \\
\hline & N & GLU & 133 & ionic & 2.83 \\
\hline & C & ASP & 106 & H-donor & 3.32 \\
\hline & O & GLU & 104 & H-donor & 3.02 \\
\hline & N & ASP & 106 & ionic & 3.96 \\
\hline & N & GLU & 145 & ionic & 3.9 \\
\hline 3 & N & ASP & 106 & ionic & 3.3 \\
\hline 4 & N & GLU & 133 & H-donor & 2.84 \\
\hline 5 & N & GSP & 106 & ionic & 3.75 \\
\hline & GLU & 145 & ionic & 3.86 \\
\hline & N & GLU & 133 & ionic & 2.84 \\
\hline & N & GLU & 133 & ionic & 3.82
\end{tabular}

Table S14. Interaction report of each conformer of D4 compound. Number of conformer, Atom of compound, Amino acid in HsTIM, Type of interaction and Distance in angstroms.

\begin{tabular}{c|l|c|c|c|c} 
Conformer & Ligand & \multicolumn{2}{c}{ Residues in HsTIM } & Interaction & Distance \\
\hline 1 & S & GLY & 210 & H-donor & 2.94 \\
\hline & S & VAL & 212 & H-donor & 3.68 \\
\hline & O & LYS & 13 & H-acceptor & 2.86 \\
\hline & O & LYS & 13 & ionic & 2.86 \\
\hline & S & GLY & 210 & H-donor & 2.96 \\
\hline & S & VAL & 212 & H-donor & 3.9 \\
\hline & O & LYS & 13 & H-acceptor & 2.86 \\
\hline & O & LYS & 13 & ionic & 2.86 \\
\hline & 6-ring & GLY & 232 & pi-H & 4.16 \\
\hline & 6-ring & ALA & 73 & pi-H & 4.67 \\
\hline & S & ASN & 15 & H-donor & 3.55 \\
\hline & O & LYS & 13 & H-acceptor & 2.95
\end{tabular}




\begin{tabular}{c|l|c|c|c|c} 
Conformer & Ligand & \multicolumn{2}{|c}{ Residues in HsTIM } & Interaction & Distance \\
\hline & O & LYS & 13 & ionic & 2.97 \\
\hline & 6-ring & ALA & 73 & pi-H & 4.38 \\
\hline 4 & O & LYS & 68 & H-acceptor & 3.28 \\
\hline & S & LYS & 112 & H-acceptor & 3.51 \\
\hline 5 & O & LYS & 68 & ionic & 3.09 \\
\hline & O & TRP & 191 & H-acceptor & 3.21
\end{tabular}

Table S15. Toxicity - PreADMET | Prediction of ADME/Tox of compounds T1-T5 and D4.

T1.-

algae_at 0.0451961

Ames_test mutagen

Carcino_Mouse

positive

daphnia_at 0.127897

hERG_inhibition high_risk

medaka_at 0.0335621

minnow_at 0.0280155

TA100 10RLI negative

TA100_NA negative

TA1535_10RLI negative

TA1535_NA positive

T3.

algae_at $\quad 0.00859781$

Ames_test mutagen

Carcino_Mouse negative

Carcino_Rat negative

daphnia_at 0.0154404

hERG_inhibition medium_risk

medaka_at 0.000516688

minnow_at 0.000664616

TA100_10RLI negative

TA100_NA negative

TA1535_10RLI negative

TA1535_NA negative

T5.

algae_at 0.00416684

Ames_test mutagen

Carcino_Mouse negative

Carcino_Rat positive

daphnia_at 0.0219124

hERG_inhibition medium_risk

medaka_at 0.000884984

minnow_at 0.00121519

TA100_10RLI negative

TA100 NA negative

TA1535_10RLI positive

TA1535_NA negative
T2.-

algae_at 0.00554922

Ames_test mutagen

Carcino_Mouse negative

Carcino_Rat negative

daphnia_at 0.00650143

hERG_inhibition medium_risk

medaka_at 0.000116801

minnow_at0.000129914

TA100 10RLI negative

TA100_NA negative

TA1535_10RLI negative

TA1535_NA negative

T4.

algae at $\quad 0.0318207$

Ames_test mutagen

Carcino_Mouse negative

Carcino_Rat negative

daphnia_at 0.179538

hERG_inhibition medium_risk

medaka_at 0.05414

minnow_at 0.0876528

TA100_10RLI negative

TA100_NA negative

TA1535 10RLI negative

TA1535_NA negative

D4.

algae_at 0.0162351

Ames_test mutagen

Carcino_Mouse negative

Carcino_Rat negative

daphnia_at 0.0261622

hERG_inhibition ambiguous

medaka_at 0.00190628

minnow at 0.00152966

TA100_10RLI positive

TA100 NA negative

TA1535_10RLI negative

TA1535_NA negative

Table S16. ADME - PreADMET | Prediction of ADME/Tox of compounds T1-T5 and D4.

T1.-

BBB 0.0139453

Buffer_solubility_mg_L

Caco2 21.0136

CYP_2C19_inhibition

CYP 2C9 inhibition Non

CYP_2D6_inhibition Non

CYP_2D6_substrate Non

CYP_3A4_inhibition Non

CYP_3A4_substrate Non

HIA 95.124084

MDCK 9.16919

Pgp_inhibition Non

Plasma_Protein_Binding

Skin_Permeability $\quad-2.95411$

SKlogD_value $\quad 2.2739$

SKlogP_value $\quad 2.2739$

SKlogS_buffer $\quad-2.663820 * *$

SKlogS_pure $\quad-4.75283$

T3.- $\quad 0.384245$

Buffer_solubility_mg_L

221.745

7.12722

$874.844^{* * *}$

Non

Caco2 25.9121

https://biointerfaceresearch.com/
T2.-

BBB 0.0215146

Buffer_solubility_mg_L

Caco2 21.4132

CYP_2C19_inhibition

CYP_2C9_inhibition Inhibitor

CYP_2D6_inhibition Non

CYP_2D6_substrate Non

CYP 3A4_inhibition Non

CYP_3A4_substrate Weakly

HIA $\quad 98.49618$

MDCK 0.0589242

Pgp_inhibition Inhibitor

Plasma_Protein_Binding $\quad 94.136555$

Pure_water_solubility_mg_L 0.00538287

Skin_Permeability $\quad-2.34608$

SKlogD_value $\quad 4.41304$

SKlogP_value $\quad 5.66104$

SKlogS buffer $\quad-6.97946$

SKlogS_pure $\quad-7.93446$

T4.

BBB 0.0268428

Buffer_solubility_mg_L

Caco2 54.4744
0.0485304

Inhibitor

68065.1 


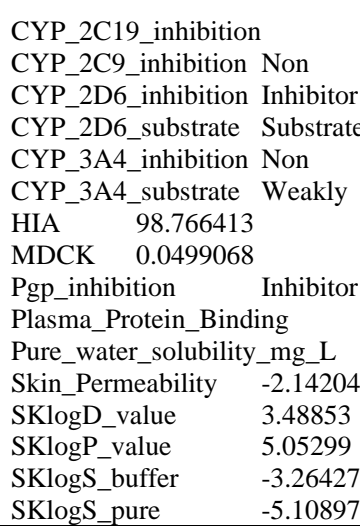

T5.

BBB 9.45103

Buffer_solubility_mg_L

$\mathrm{Caco} 256.4024$

CYP_2C19_inhibition

CYP_2C9_inhibition Non

CYP_2D6_inhibition Inhibitor

CYP 2D6 substrate Substrate

CYP_3A4_inhibition Non

CYP_3A4_substrate Weakly

HIA 97.105389

MDCK 0.872546

Pgp_inhibition Inhibitor

Plasma_Protein_Binding

Pure_water_solubility_mg_L

Skin_Permeability $\quad-3.25132$

SKlogD_value $\quad 1.3476$

SKlogP value $\quad 4.47652$

SKlogS_buffer $\quad-3.54971$

SKlogS_pure $\quad-3.01827$
Non

CYP_2C19_inhibition

CYP_2C9_inhibition Non

CYP_2D6_inhibition Non

CYP_2D6_substrate Substrate

CYP_3A4_inhibition Non

CYP_3A4_substrate Substrate

HIA 96.023819

MDCK $\quad 57.2976$

Pgp_inhibition Non

Plasma_Protein_Binding

Pure_water_solubility_mg_L

Skin_Permeability $\quad-3.72035$

SKlogD_value $\quad 0.682080$

SKlogP_value $\quad 2.02606$

SKlogS_buffer $\quad-0.7347$

SKlogS_pure $\quad-1.48874$

D4.-

BBB 0.0349711

Buffer_solubility_mg_L

Caco2 19.32

CYP_2C19_inhibition

CYP_2C9_inhibition Non

CYP_2D6_inhibition Non

CYP_2D6_substrate Non

CYP_3A4_inhibition Inhibitor

CYP_3A4_substrate Weakly

HIA 40.443246

MDCK 1.68617

Pgp_inhibition Inhibitor

Plasma_Protein_Binding

Pure_water_solubility_mg_L

Skin_Permeability $\quad-3.79902$

SKlogD_value $\quad 1.85403$

SKlogP value $\quad 1.85403$

SKlogS_buffer $\quad-6.11097$

SKlogS_pure $\quad-6.74704$

Inhibitor

49.658153

11991.8

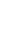

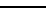

0.34811

Non

94.330258

0.0804723

64.300766
383.156

Table S17. Properties predicted by PhysChem - ACD/Labs of compounds T1-T5 and D4.

T1.-

Density:

Boiling Point: $\quad 615.5 \pm 55.0^{\circ} \mathrm{C}$ at $760 \mathrm{mmHg}$

Vapour Pressure: $\quad 0.0 \pm 1.9 \mathrm{mmHg}$ at $25^{\circ} \mathrm{C}$

Enthalpy of Vaporization: $\quad 96.0 \pm 3.0 \mathrm{~kJ} / \mathrm{mol}$

Flash Point: $\quad 326.0 \pm 31.5^{\circ} \mathrm{C}$

Index of Refraction:

Molar Refractivity:

\#H bond acceptors: 7

\#H bond donors:

\#Freely Rotating Bonds:

\#Rule of 5 Violations: 0

ACD/LogP: $\quad 4.16$

$\mathrm{ACD} / \operatorname{LogD}(\mathrm{pH} 5.5): 2.24$

ACD/BCF (pH 5.5): 9.04

$\mathrm{ACD} / \mathrm{KOC}(\mathrm{pH} 5.5): 41.47$

$\mathrm{ACD} / \operatorname{LogD}(\mathrm{pH} 7.4): 1.27$

$\mathrm{ACD} / \mathrm{BCF}$ (pH 7.4): 1.00

$\mathrm{ACD} / \mathrm{KOC}(\mathrm{pH} 7.4): 4.53$

Polar Surface Area: $108 \AA 2$

Polarizability:

Surface Tension:

Molar Volume:

T3.

Density: $\quad 1.2 \pm 0.1 \mathrm{~g} / \mathrm{cm} 3$

Boiling Point: $\quad 506.0 \pm 50.0^{\circ} \mathrm{C}$ at $760 \mathrm{mmHg}$

Vapour Pressure: $\quad 0.0 \pm 1.3 \mathrm{mmHg}$ at $25^{\circ} \mathrm{C}$

Enthalpy of Vaporization: $\quad 77.6 \pm 3.0 \mathrm{~kJ} / \mathrm{mol}$

Flash Point: $\quad 259.8 \pm 30.1{ }^{\circ} \mathrm{C}$

Index of Refraction: 1.572

Molar Refractivity: $\quad 108.2 \pm 0.3 \mathrm{~cm} 3$

\#H bond acceptors: 3

\#H bond donors: $\quad 0$

\#Freely Rotating Bonds:

\#Rule of 5 Violations: 1

$\mathrm{ACD} / \log \mathrm{P}$ :

ACD/LogD (pH 5.5): 2.63

$\mathrm{ACD} / \mathrm{BCF}(\mathrm{pH} 5.5): \quad 16.20$

$\mathrm{ACD} / \mathrm{KOC}(\mathrm{pH} 5.5): 56.14$

$\mathrm{ACD} / \operatorname{LogD}(\mathrm{pH} 7.4): 4.34$

$\mathrm{ACD} / \mathrm{BCF}(\mathrm{pH} 7.4): 835.29$

https://biointerfaceresearch.com/
T2.

Density: $\quad 1.4 \pm 0.1 \mathrm{~g} / \mathrm{cm} 3$

Boiling Point: $\quad 706.8 \pm 60.0^{\circ} \mathrm{C}$ at $760 \mathrm{mmHg}$

Vapour Pressure: $\quad 0.0 \pm 2.4 \mathrm{mmHg}$ at $25^{\circ} \mathrm{C}$

Enthalpy of Vaporization: $\quad 108.6 \pm 3.0 \mathrm{~kJ} / \mathrm{mol}$

Flash Point: $\quad 381.2 \pm 32.9^{\circ} \mathrm{C}$

Index of Refraction: 1.675

Molar Refractivity: $\quad 123.6 \pm 0.3 \mathrm{~cm} 3$

\#H bond acceptors: 6

\#H bond donors:

\#Freely Rotating Bonds:

\#Rule of 5 Violations: 1

$\mathrm{ACD} / \log \mathrm{P}: \quad 6.42$

$\mathrm{ACD} / \operatorname{LogD}(\mathrm{pH} 5.5): 4.16$

$\mathrm{ACD} / \mathrm{BCF}(\mathrm{pH} 5.5): \quad 399.19$

$\mathrm{ACD} / \mathrm{KOC}(\mathrm{pH} 5.5): 1019.71$

$\mathrm{ACD} / \operatorname{LogD}(\mathrm{pH} 7.4): 2.64$

ACD/BCF (pH 7.4): 12.08

$\mathrm{ACD} / \mathrm{KOC}(\mathrm{pH} 7.4): 30.85$

Polar Surface Area: $90 \AA 2$

Polarizability: $\quad 49.0 \pm 0.510-24 \mathrm{~cm} 3$

Surface Tension: $\quad 63.7 \pm 3.0 \mathrm{dyne} / \mathrm{cm}$

Molar Volume: $\quad 329.0 \pm 3.0 \mathrm{~cm} 3$

\section{T4.}

Density: $\quad 1.2 \pm 0.1 \mathrm{~g} / \mathrm{cm} 3$

Boiling Point: $\quad 575.7 \pm 50.0^{\circ} \mathrm{C}$ at $760 \mathrm{mmHg}$

Vapour Pressure: $\quad 0.0 \pm 1.6 \mathrm{mmHg}$ at $25^{\circ} \mathrm{C}$

Enthalpy of Vaporization: $\quad 86.2 \pm 3.0 \mathrm{~kJ} / \mathrm{mol}$

Flash Point: $\quad 302.0 \pm 30.1{ }^{\circ} \mathrm{C}$

Index of Refraction: 1.601

Molar Refractivity: $\quad 109.8 \pm 0.5 \mathrm{~cm} 3$

\#H bond acceptors: 6

\#H bond donors: 1

\#Freely Rotating Bonds:

\#Rule of 5 Violations: 0

ACD/LogP: $\quad 0.17$

$\mathrm{ACD} / \operatorname{LogD}(\mathrm{pH} 5.5):-2.11$

$\mathrm{ACD} / \mathrm{BCF}$ (pH 5.5): 1.00

$\mathrm{ACD} / \mathrm{KOC}$ (pH 5.5): 1.00

$\mathrm{ACD} / \operatorname{LogD}(\mathrm{pH} 7.4):-0.62$

$\mathrm{ACD} / \mathrm{BCF}$ (pH 7.4): 1.00 
ACD/KOC (pH 7.4): 2894.38

Polar Surface Area: $35 \AA 2$

Polarizability: $\quad 42.9 \pm 0.510-24 \mathrm{~cm} 3$

Surface Tension: $\quad 40.4 \pm 3.0 \mathrm{dyne} / \mathrm{cm}$

Molar Volume: $\quad 328.8 \pm 3.0 \mathrm{~cm} 3$

T5.

Density: $\quad 1.1 \pm 0.1 \mathrm{~g} / \mathrm{cm} 3$

Boiling Point: $\quad 530.8 \pm 35.0^{\circ} \mathrm{C}$ at $760 \mathrm{mmHg}$

Vapour Pressure: $\quad 0.0 \pm 1.5 \mathrm{mmHg}$ at $25^{\circ} \mathrm{C}$

Enthalpy of Vaporization: $\quad 83.6 \pm 3.0 \mathrm{~kJ} / \mathrm{mol}$

Flash Point: $\quad 246.3 \pm 24.6{ }^{\circ} \mathrm{C}$

Index of Refraction: 1.567

Molar Refractivity: $\quad 121.0 \pm 0.3 \mathrm{~cm} 3$

\#H bond acceptors: 4

\#H bond donors:

\#Freely Rotating Bonds:

\#Rule of 5 Violations: 0

$\mathrm{ACD} / \log \mathrm{P}$ 4.71

$\mathrm{ACD} / \operatorname{LogD}(\mathrm{pH} 5.5):-0.42$

$\mathrm{ACD} / \mathrm{BCF}(\mathrm{pH} 5.5): 1.00$

$\mathrm{ACD} / \mathrm{KOC}(\mathrm{pH} 5.5): 1.00$

$\mathrm{ACD} / \operatorname{LogD}(\mathrm{pH} 7.4): 0.51$

ACD/BCF (pH 7.4): 1.00

$\mathrm{ACD} / \mathrm{KOC}(\mathrm{pH} 7.4): 1.00$

Polar Surface Area: $30 \AA 2$

Polarizability: $\quad 48.0 \pm 0.510-24 \mathrm{~cm} 3$

Surface Tension: $\quad 46.4 \pm 3.0$ dyne/cm

Molar Volume: $\quad 370.4 \pm 3.0 \mathrm{~cm} 3$
$\mathrm{ACD} / \mathrm{KOC}$ (pH 7.4): 1.00

Polar Surface Area: $53 \AA 2$

Polarizability: $\quad 43.5 \pm 0.510-24 \mathrm{~cm} 3$

Surface Tension: $\quad 42.4 \pm 7.0$ dyne $/ \mathrm{cm}$

Molar Volume: $\quad 320.6 \pm 7.0 \mathrm{~cm} 3$

D4.

Density: $\quad 1.7 \pm 0.1 \mathrm{~g} / \mathrm{cm} 3$

Boiling Point: $\quad 648.7 \pm 65.0^{\circ} \mathrm{C}$ at $760 \mathrm{mmHg}$

Vapour Pressure: $\quad 0.0 \pm 2.0 \mathrm{mmHg}$ at $25^{\circ} \mathrm{C}$

Enthalpy of Vaporization: $\quad 100.5 \pm 3.0 \mathrm{~kJ} / \mathrm{mol}$

Flash Point: $\quad 346.1 \pm 34.3{ }^{\circ} \mathrm{C}$

Index of Refraction: 1.788

Molar Refractivity: $\quad 110.6 \pm 0.5 \mathrm{~cm} 3$

\#H bond acceptors: 11

\#H bond donors: 2

\#Freely Rotating Bonds:

\#Rule of 5 Violations: 1

ACD/LogP

1.57

$\mathrm{ACD} / \operatorname{LogD}(\mathrm{pH} 5.5):-3.25$

$\mathrm{ACD} / \mathrm{BCF}(\mathrm{pH} 5.5): 1.00$

$\mathrm{ACD} / \mathrm{KOC}(\mathrm{pH} 5.5): 1.00$

$\mathrm{ACD} / \operatorname{LogD}(\mathrm{pH} 7.4):-4.12$

$\mathrm{ACD} / \mathrm{BCF}(\mathrm{pH} 7.4): 1.00$

$\mathrm{ACD} / \mathrm{KOC}$ (pH 7.4): 1.00

Polar Surface Area: $229 \AA 2$

Polarizability: $\quad 43.9 \pm 0.510-24 \mathrm{~cm} 3$

Surface Tension: $\quad 73.0 \pm 7.0$ dyne $/ \mathrm{cm}$

Molar Volume: $\quad 261.7 \pm 7.0 \mathrm{~cm} 3$ 